\title{
Análise dos fatores preditores de mortalidade em pacientes incidentes em hemodiálise
}

Tese apresentada à Faculdade de Medicina da Universidade de São Paulo para obtenção do título de Doutor em Ciências

Programa de Nefrologia Orientadora: Dra. Vanda Jorgetti

São Paulo 2015 
Preparada pela Biblioteca da

Faculdade de Medicina da Universidade de São Paulo

Creprodução autorizada pelo autor

Magalhães, Luciene Pereira

Análise dos fatores preditores de mortalidade em pacientes incidentes em hemodiálise / Luciene Pereira Magalhães. -- São Paulo, 2015.

Tese(doutorado)--Faculdade de Medicina da Universidade de São Paulo. Programa de Nefrologia.

Orientadora: Vanda Jorgetti.

Descritores: 1.Insuficiência renal crônica 2.Mortalidade 3.Doenças cardiovasculares 4.Diálise renal 5.Fatores de risco 6.Uremia 7.Desnutrição 8.Inflamação 9.Serviços médicos de emergência

USP/FM/DBD-493/15 


\section{Dedicatória}

À minha FAMíLIA, pelo apoio dispensado incondicionalmente, dandome força e incentivo de sempre seguir em frente na determinação de realizar os meus objetivos e aos AMIGOS pelo carinho, companheirismo e apoio. 


\section{Agradecimentos}

Agora é tempo de reconhecer o apoio recebido, apreciar o incentivo e puxões de orelha bem vindos, celebrar o fruto dos anos de trabalho, o que não seria possível sem as pessoas que tenho ao meu redor e me inspiram de diversas maneiras. Desta forma, é tempo de agradecer e apreciar estas pessoas especiais que fazem minha vida ter sentido e valer a pena...

Primeiramente a Deus, pelo dom da vida e pela graça de acordar com saúde e força para seguir adiante diariamente, pela família maravilhosa, pela dádiva de estudar e por permitir que eu percorresse caminhos tão nobres e conhecesse pessoas tão especiais, me agraciando com grandes oportunidades. Nos momentos mais difíceis, pude perceber sua presença.

Especialmente aos meus pais Lucílio e Leonídia, por terem nossa educação como prioridade, por apoiarem minhas escolhas e me oferecerem condições para chegar até aqui. Obrigada por ser exemplo de dedicação e vida, pois sem este suporte eu nada seria.

Aos meus irmãos Lucius e Lúcelia, pelo carinho, amizade, atenção, companheirismo, incentivo e por ter me dado suporte necessário nos momentos mais difíceis desta jornada.

Ao meus familiares, em especial, tios e primos, maternos e paternos, presentes nos momentos alegres e difíceis da minha vida e que tiveram a compreensão da minha ausência por estes anos por dedicação aos meus estudos e mesmo à distância torcem por meu sucesso.

Ao Programa de Pós-Graduação da Faculdade de Medicina da USP, pela realização deste trabalho, aos professores pelo conhecimento compartilhado e por mais esta grande oportunidade de crescimento profissional.

À minha orientadora Profá. Dra. Vanda Jorgetti, por ter dispensado incontáveis horas de dedicação na orientação deste trabalho, por sua paciência com minhas limitações, corrigindo meus erros e me incentivando a enfrentar os desafios. Foi além de tudo mais que orientadora, amiga, irmã, companheira de trabalho, que me concedeu muitas oportunidades e me permitiu crescer profissional e pessoalmente, compartilhando comigo seus conhecimentos generosamente. Com você aprendi ensinamentos muito maiores do que estão descritos nesse trabalho, que vou guardar comigo não apenas em minha vida profissional, mas também pessoal. Sua forma de conduzir a vida ao mesmo 
tempo com bravura e ternura é admirável, um exemplo a ser seguido de pesquisadora e profissional.

À minha "co-orientadora" Profa. Dra. Rosa Moysés, por sua atenção, estímulo, colaboração científica, exemplo de dedicação à Nefrologia e pela sua grande colaboração na fase das "tempestades de ideias". Aprendi muito com você.

À Dra. Melani Custódio, pela disponibilidade, orientação, dicas e recomendações que me foram úteis e pela amizade demonstrada ao longo deste percurso.

Um agradecimento especial ao Dr. Roberto Zatz e a Dra Clarice Fujihara e sua equipe, pois em meio a tanta turbulência, sempre me proporcionaram amor e carinho me fazendo ver o lado bom de tudo e fazendo com que não desistisse do objetivo final. Minha sincera admiração e agradecimento por este período que caminhamos juntos e por tudo que aprendi com vocês.

À Dra Viktoria Woronik, por quem tenho grande admiração, pela amizade, apoio na horas difíceis e pelos ensinamentos sobre a Nefrologia e sobre a vida.

Ao Dr. Benedito Pereira e Dr. Rodrigo Bueno, pela grande colaboração no início desta jornada.

Aos funcionários do HCFMUSP e do INCOR (Ambulatório, Enfermaria, Laboratório, Biblioteca, SAME) pelo profissionalismo, disponibilidade e ajuda durante este trabalho, e á todos aqueles que prestaram cuidados aos pacientes deste estudo, direta ou indiretamente.

Aos secretários da Pós-graduação da Nefrologia, Pedro e Eliana, pela ajuda dispensada em todo este tempo e auxílio nas tarefas burocráticas e pela gentileza de estarem sempre dispostos em ajudar.

Aos Amigos e colaboradores do LIM 16, pelo apoio em todas as etapas deste trabalho, em especial a Fabiana e Luciene Reis, pela ajuda inestimável no momentos mais difíceis e ao Wagner pela sua grande colaboração em todas as etapas deste trabalho, disponibilidade e paciência para me ensinar análise estatística e informática. Obrigada pelo esforço e colaboração de cada um de vocês ao longo destes anos.

Às minhas amigas/irmãs da Pós: Juliana Ferreira, Guaraciaba Ferrari e Roxana Camelo, com quem dividi muitas angústias, dúvidas, alegrias, vitórias e aprendizado. Foi um privilégio conviver com vocês. 
Aos colegas da Pós-graduação que já partiram para uma nova etapa de suas vidas, entretanto fizeram parte das etapas iniciais deste trabalho, pela prestatividade, carinho, amizade, experiências e aprendizado compartilhados: Cris Karol, Carolina Neves, Daniella Guimarães, Ana Ludmilla, Rodrigo Azevedo, Patrícia Goldenstein, Tatiana Anitelli e Verônica Gouveia.

Ao colegas e amigos do ambulatório e da Pós-graduação atual, Melissa, Geovanna, César, Carolina, Maria Júlia, Janaína e Aline pelos momentos que dividimos durante este período.

À toda equipe da Nefrologia da Santa Casa de São Paulo, Dra. Yvoti Sens, Dr. Pedro Jabur, Dr. Luiz Antonio Miorim e Dr. Ferraz, pela amizade, incentivo constantes e por todos os conhecimentos compartilhados. O exemplo do trabalho de vocês com certeza influenciou nas minhas escolhas pela Nefrologia.

À Dr $r^{a}$ Patrícia Malafronte (Papá) e a Dra Andrea Olivares Magalhães pelo incentivo e ingresso na Pós-graduação. Foi a partir de vocês que tudo isto começou.

À Equipe da Samarim, Drs. Alexandre, Eduardo Garcia, Eduardo Cantoni, Eliana Menezes, Lília Leister, Maria Fernanda, minhas amigas e companheiras nefropediatras, equipe de enfermagem e meus pacientes, vocês me deram força para prosseguir apesar de todos os obstáculos que surgiram ao longo dessa caminhada. Muito obrigada, pelo apoio e incentivo.

Aos amigos do Hospital Brigadeiro, em especial Adriana Gelmetti, Lilian Rocha, Maria Clara, Patrícia Manzani, Cristiane Toledo, Carina Moreno, Leda Zecketto, Marcus Taver, João Nastri, Andrea Gaspar, aos residentes da Nefrologia (Lívia, Mabel e Marcus) e ao corpo de enfermagem pelo incentivo constante e pela força dada, não me deixando cair nem desistir em momento algum. Obrigada pelo carinho e pela compreensão na troca de horários, que muito me ajudou no término deste trabalho.

Aos colegas e amigos do HCOR, em especial Dra Leda Lotaiff, Mônica Pedreira, Celia Novelino, Verônica Torres e Antônio Cordeiro pela amizade, apoio e incentivo nesta jornada.

A Dr ${ }^{a}$ Rosilene Motta, minha admiração e gratidão pela sua valiosa colaboração e disponibilidade na revisão do texto e na análise estatística deste trabalho e ao Dr Isac Castro, pela ajuda para as análises estatísticas e conselhos importantes para o término deste estudo e principalmente pela paciência com que me repassou as informações estatísticas, de forma simples e agradável. 
Agradeço à Fundação de Amparo à Pesquisa do Estado de São Paulo (FAPESP) pelo suporte financeiro para o desenvolvimento deste trabalho.

Aos Centros de Diálise por ter me recebido de portas abertas, pelo auxílio nas coletas de dados e acesso às informações dos pacientes, sempre disponíveis para contribuir neste processo. Obrigada pelo cuidado e imprescindível apoio nesta etapa.

Ao pacientes dialíticos que tive o privilégio de conhecer, pela confiança e carinho demonstrados e pela sua colaboração, muito contribuíram para esta pesquisa, sem a qual seria impossível a realização deste trabalho.

Aos meus amigos de "Ionge e de perto" que ouviram muito "não posso" às pessoas anônimas, mas que não desistiram de mim.

Às muitas pessoas que tiveram participação significativa, contribuindo de algum modo para a realização deste trabalho e que, por extensa que seria a lista seus nomes não estão aqui citados.

Cabe-me dizer, por fim, que durante esta longa jornada de conhecimento, aprendizado, experiência profissional, científica e de vida, o desafio e as motivações foram enormes, com alguns momentos de turbulência, angústia e sofrimento, mas ultrapassados pelos afetos, carinho e amizade daqueles que acreditam em mim. 
Tudo tem o seu tempo determinado, e há tempo para todo o propósito debaixo do céu. Há tempo de nascer, e tempo de morrer; Tempo de plantar, e tempo de arrancar o que se plantou; Tempo de matar, e tempo de curar; Tempo de derrubar, e tempo de edificar; Tempo de chorar, e tempo de rir; Tempo de prantear, e tempo de dançar; Tempo de espalhar pedras, e tempo de ajuntar pedras; Tempo de abraçar, e tempo de afastar-se de abraçar; Tempo de buscar, e tempo de perder; Tempo de guardar, e tempo de lançar fora; Tempo de rasgar, e tempo de coser; Tempo de estar calado, e tempo de falar; Tempo de amar, e tempo de odiar; Tempo de guerra, e tempo de paz.

(Eclesiastes, 3:1-8) 


\section{SUMÁRIO}

Lista de Figuras

Lista de Tabelas

Lista de abreviaturas e siglas

Resumo

Summary

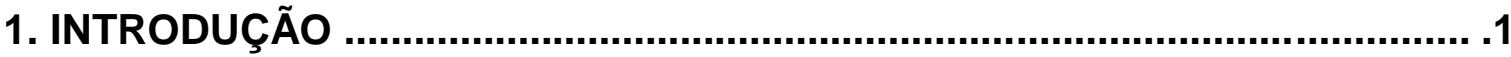

2. OBJETIVO

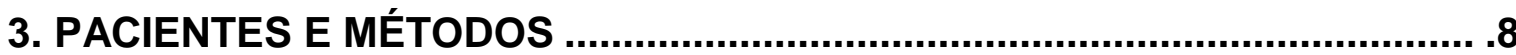

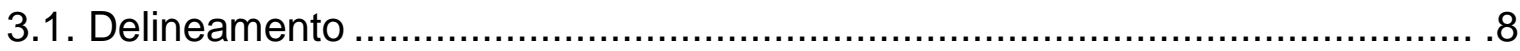

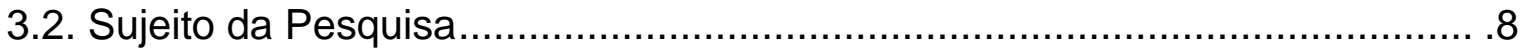

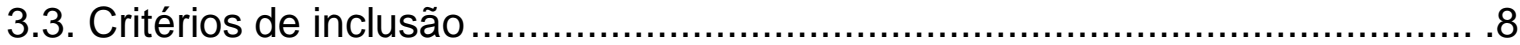

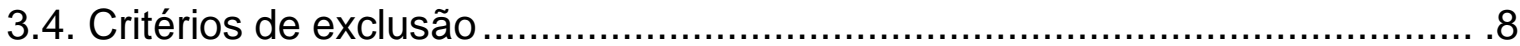

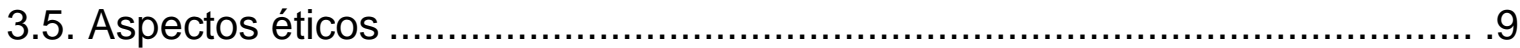

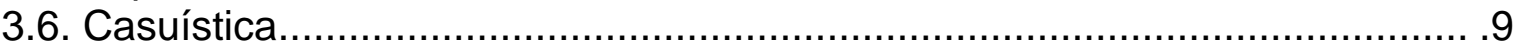

3.7. Parâmetros clínicos avaliados ............................................................... 9

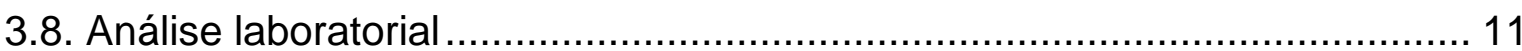

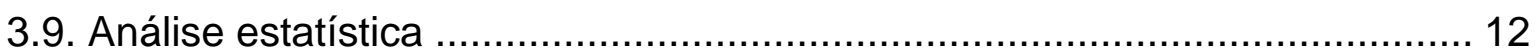

4. RESULTADOS

4.1. Características clínicas e principais fatores de risco detectados nos pacientes admitidos na Emergência........................................................... 13

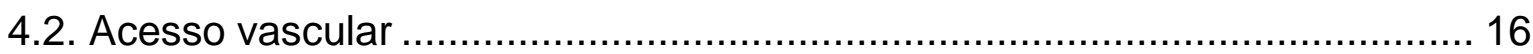

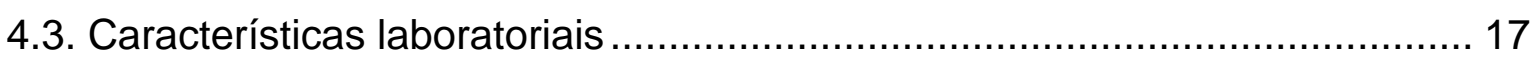

4.4. Comparações dos resultados laboratoriais na admissão entre pacientes

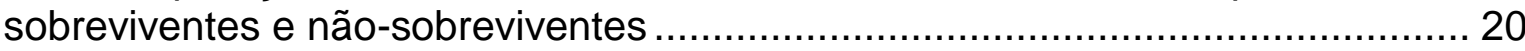

4.5. Principais medicações empregadas pelos pacientes sobreviventes e nãosobreviventes durante 0 seguimento ............................................................... 21

4.6. Principais complicações que ocorreram nos pacientes sobreviventes e nãosobreviventes ao longo do seguimento ............................................................. 22

4.7. Análise de sobrevida dos pacientes de acordo com a presença ou não de

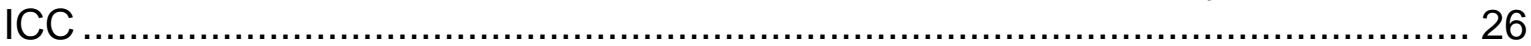

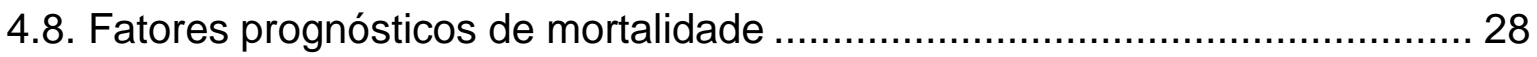

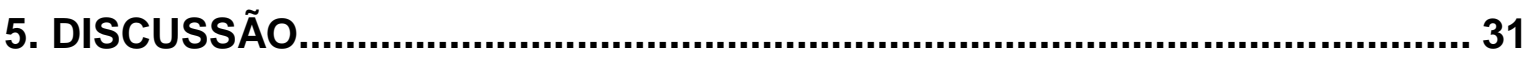

6. CONCLUSÕES

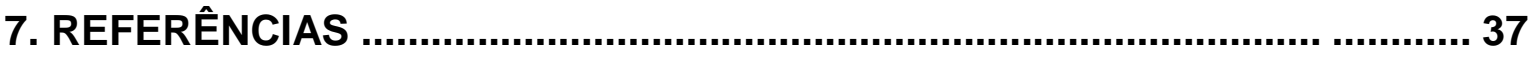

8. APÊNDICE 


\section{LISTA DE FIGURAS}

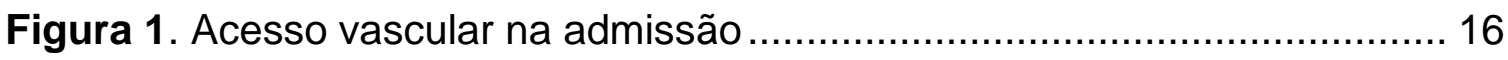

Figura 2. Acesso vascular ao fim do primeiro ano........................................ 16

Figura 3. Infecções ocorridas ao longo do seguimento nos pacientes sobreviventes e não-sobreviventes

Figura 4. Antecedentes de eventos cardiovasculares ocorridos ao longo do seguimento nos pacientes sobreviventes e nãosobreviventes..... 22

Figura 5. Curva de sobrevida de acordo com a presença de ICC 23

Figura 6. Curva de sobrevida em pacientes sem ICC de acordo com tipo de acesso vascular

Figura 7. Curva de sobrevida em pacientes com ICC de acordo com tipo de acesso vascular 


\section{LISTA DE TABELAS}

Tabela 1. Características clínicas e principais fatores de risco dos pacientes admitidos na Emergência ......................................................................... 14

Tabela 2. Principais medicações usadas pelos pacientes na admissão ............... 15

Tabela 3. Características laboratoriais dos pacientes na admissão .................... 18

Tabela 4. Comparação das características clínicas e fatores de risco detectados na admissão entre pacientes sobreviventes e não-sobreviventes ..... 19

Tabela 5. Comparação dos resultados laboratoriais detectadas na admissão entre pacientes sobreviventes e não-sobreviventes............................................ 20

Tabela 6. Principais medicações empregadas ao longo do seguimento entre pacientes sobreviventes e não-sobreviventes

Tabela 7.Características clínicas dos pacientes sobreviventes e nãosobreviventes de acordo com a presença ou não de ICC

Tabela 8. Características laboratoriais dos pacientes sobreviventes e nãosobreviventes com e sem insuficiência cardíaca congestiva 25

Tabela 9. Fatores de risco e mortalidade incluindo todos os pacientes 29

Tabela 10. Fatores de risco e mortalidade incluindo os pacientes sem insuficiência

Tabela 11. Fatores de risco e mortalidade incluindo os pacientes com insuficiência cardíaca congestiva 


\section{LISTA ABREVIATURAS E SIGLAS}

AAS: Ácido acetilsalicílico

AE: Átrio Esquerdo

BRA: Bloqueador do Receptor da Angiotensina

CV: Calcificação Vascular

DAC: Doença Arterial Coronariana

DVP: Doença Vascular Periférica

DCV: Doença Cardiovascular

DM: Diabetes Mellitus

DMO: Distúrbio do Metabolismo Mineral e Ósseo

DRC: Doença Renal Crônica

EUA: Estados Unidos da América

FAV : Fístula Arteriovenosa

FGF23 : Fator de Crescimento Fibroblástico 23

HAS: Hipertensão Arterial Sistêmica

HDL: High density lipoprotein colesterol

HPTS: Hiperparatireoidismo Secundário

HVE: Hipertrofia Ventricular Esquerda

IAM: Infarto Agudo do Miocárdio

IC: Intervalo de Confiança

ICC: Insuficiência Cardíaca Congestiva

IECA: inibidor da Enzima Conversora de Angiotensina

LDL: Low density lipoprotein cholesterol

KDIGO: Kidney Disease Improving Global Outcomes

NKFKDOQI: The National Kidney Foundation Kidney Disease Outcomes Quality

Initiative

MS: Morte Súbita

ODR: Osteodistrofia Renal

HR: Hazard ratio

PA: Pressão Arterial

PCR: Proteína C Reativa

PTH: Paratormônio

SBN: Sociedade Brasileira de Nefrologia

SCA: Síndrome Coronariana Aguda

SRAA: Sistema Renina-Angiotensina-Aldosterona

USP, Universidade de São Paulo

VDR: Receptor de Vitamina D

VE: Ventrículo Esquerdo

VLDL: Very low density lipoprotein cholesterol

VS. Versus 


\section{Resumo}

Introdução: A doença renal crônica afeta de 10 a 15 \% da população adulta mundial e a piora da função renal, se associa com várias complicações, tais como: desnutrição, inflamação, doenças cardiovasculares e distúrbios do metabolismo mineral. A mortalidade desses pacientes é elevada sendo de 6 a 8 vezes maior que a de indivíduos saudáveis. Cerca de $22 \%$ dos pacientes incidentes, ou seja, no primeiro ano de diálise, vão a óbito. O objetivo do presente estudo foi avaliar as características clínicas, laboratoriais de pacientes incidentes em diálise além de identificar fatores de risco que contribuíssem para a mortalidade desses pacientes. Métodos: Estudamos 424 pacientes com sinais e sintomas de uremia e indicação de tratamento dialítico admitidos no serviço de emergência do Hospital das Clínicas entre Janeiro de 2006 e Dezembro de 2012. O tempo de acompanhamento foi de um ano. Analisamos os parâmetros clínicos, tipo de via de acesso para hemodiálise, fatores de risco ligados a doenças cardiovasculares e as alterações do metabolismo mineral bem como eventos clínicos ocorridos durante o seguimento. Avaliamos a sobrevida e os fatores que influenciaram a sobrevida dos pacientes, pela curva de Kaplan-Meier e análise de regressão de Cox, respectivamente. Resultados: A média de idade foi de $50 \pm 18$ anos, $58,7 \%$ eram homens e $69,1 \%$ brancos. Hipertensão arterial foi a principal etiologia da doença renal primária $(31,8 \%)$ seguida de DM $(29,5 \%)$. Os principais fatores de risco encontrados foram tabagismo (19,6\%), dislipidemia (48,8\%), doenças cardiovasculares (41\%) e na admissão a maioria dos pacientes não tinha acesso vascular para hemodiálise $(89,4 \%)$. Os resultados dos exames laboratoriais revelaram que a maioria dos pacientes estava anêmico $(83,7 \%)$, com níveis de PCR elevados (79,9\%). Os distúrbios do metabolismo mineral como hipocalcemia, hiperfosfatemia, elevação dos níveis de paratormônio e diminuição dos níveis de $25(\mathrm{OH})$ vitamina $D$ estavam presentes em praticamente todos os pacientes. Ao término de um ano, 60 pacientes faleceram (14,1\%). Esses pacientes eram significativamente mais idosos, apresentavam sinais de insuficiência cardíaca congestiva, de desnutrição, de inflamação, níveis reduzidos de $25(\mathrm{OH})$ vitamina $\mathrm{D}$, desenvolveram maior número de infecções e não tinham acesso vascular definitivo para hemodiálise. Conclusões: A avaliação conjunta de parâmetros clínicos, laboratoriais e dos fatores de risco revelou que a idade mais avançada, presença de insuficiência cardíaca congestiva, desnutrição, inflamação, deficiência de vitamina $D$ e a falta de via de acesso para hemodiálise foram fatores preditores de mortalidade em pacientes incidentes em hemodiálise.

Descritores: Insuficiência renal crônica; Mortalidade; Doenças cardiovasculares; Diálise renal; Fatores de risco; Uremia; Desnutrição; Inflamação; Serviços médicos de emergência. 


\section{Summary}

Introduction: Chronic kidney disease affects $10-15 \%$ of the world adult population, and the worsening of renal function is associated with several complications, such as malnutrition, inflammation, cardiovascular diseases and disorders of mineral metabolism. Mortality of those patients is high and 6 to 8 times higher than that of healthy individuals. About $22 \%$ of incident patients, that is, during the first year of dialysis, will die. The aim of this study was to evaluate the clinical and laboratory characteristics of incident dialysis patients and identify risk factors that contribute to the mortality of these patients. Methods: We studied 424 patients with signs and symptoms of uremia and dialysis indication admitted to the emergency service at Hospital das Clínicas between January 2006 and December 2012. Follow-up time was one year. We analyzed the clinical parameters, type of hemodialysis access road, risk factors linked to cardiovascular diseases and changes in mineral metabolism as well as clinical events occurred during follow-up. We evaluated survival and the factors that influenced patient survival by Kaplan-Meier curves and Cox regression analysis respectively. Results: Mean age was $50 \pm 18$ years old; $58.7 \%$ were males and $69.1 \%$ were white. Hypertension was the main cause of primary kidney disease $(31.8 \%)$ followed by DM (29.5\%). Major risk factors found were smoking (19.6\%), dyslipidemia (48.8\%), cardiovascular disease (41\%), and upon admission most patients had no vascular access for hemodialysis (89.4\%). Results of laboratory tests showed that most patients were anemic $(83.7 \%)$, with high CRP levels (79.9\%). Disturbances of mineral metabolism such as hypocalcemia, hyperphosphatemia, elevated parathyroid hormone levels and decreased levels of $25(\mathrm{OH})$ vitamin $\mathrm{D}$ were present in almost all patients. At the end of a year, 60 patients died (14.1\%). These patients were significantly older, had signs of congestive heart failure, malnutrition, inflammation, low levels of $25(\mathrm{OH})$ vitamin $\mathrm{D}$, developed greater number of infections and had no definitive vascular access for hemodialysis. Conclusions: The joint evaluation of clinical and laboratory parameters and risk factors revealed that older age, presence of congestive heart failure, malnutrition, inflammation, vitamin $D$ deficiency and lack of hemodialysis access road were predictors of mortality in incident patients undergoing hemodialysis.

Descriptors: Chronic kidney disease; Mortality; Cardiovascular diseases; Kidney dialysis; Risk factors; Uremia; Malnutrition; Inflammation; Emergency medical services. 


\section{INTRODUÇÃO}

A doença renal crônica (DRC) é definida como qualquer alteração na estrutura e função dos rins, que persista por mais de três meses e que afete a saúde de um indivíduo, independentemente da sua causa ${ }^{1}$.

Nas últimas décadas, a DRC evoluiu como um problema de saúde pública global afetando de 10 a $15 \%$ da população adulta mundial. Vários fatores contribuíram para esse cenário, entre eles, a elevada prevalência de obesidade, hipertensão arterial sistêmica (HAS), diabetes mellitus (DM) e a maior longevidade da população².

No Brasil pouco se sabe sobre a prevalência da DRC, especialmente nos estágios iniciais da doença. Estima-se que 5\% dos indivíduos acima de 60 anos tenham algum grau de DRC. Em 2010 cerca de 1,9 milhões de pacientes em todo o mundo estavam em tratamento dialítico. O último censo da Sociedade Brasileira de Nefrologia (SBN) revelou que 97.586 pacientes realizavam esse tipo de tratamento sendo $90 \%$ deles em hemodiálise $(\mathrm{HD})^{3,4,5}$.

O diagnóstico precoce, a melhor qualidade do tratamento dialítico e o aumento do número de transplantes contribuíram para diminuir a mortalidade dos pacientes com DRC 6 . No entanto, resultados do "Global Burden of Disease Study 2013" publicados recentemente, estimaram que no mundo 956.200 óbitos foram atribuídos a DRC, representando um aumento de $134,6 \%$ em relação aos dados de 1990. Vale ressaltar que dados do United States Renal Data System (USRDS) demonstraram que, nos últimos vinte anos a mortalidade dos pacientes em hemodiálise diminuiu $28 \%$, dos tratados com diálise peritoneal $47 \%$ e dos transplantados $51 \%$. No entanto, quando a sobrevida é comparada a da população normal, ajustando-se a mortalidade para todas as causas, ela é de 6,1 a 7,8 vezes maior nos pacientes em diálise do que nos indivíduos normais, especialmente no primeiro ano de diálise quando cerca de $22 \%$ dos pacientes vão a óbito ${ }^{6,7}$. Dessa forma é importante identificar fatores de risco que associados a doença renal, contribuam para 
essa elevada mortalidade $8,9,10,11$.

As doenças cardiovasculares (DCV) são a principal causa de morte tanto na população geral como nos pacientes com DRC, aumentando sua prevalência com o declínio da função renal ${ }^{11,12}$.

Os fatores de risco tradicionais que contribuem para desenvolvimento das DCV, tais como idade, sedentarismo, HAS, DM, obesidade e dislipidemia são mais prevalentes nos pacientes com DRC que nos indivíduos com função renal normal13. A própria doença renal, per si, piora a hipertrofia ventricular e a aterosclerose, bases das complicações cardiovasculares desses pacientes além de desencadear e manter um estado inflamatório crônico, anemia, desnutrição, hipervolemia e alterações do metabolismo mineral13,14.

As DCV mais prevalentes nesses pacientes são insuficiência cardíaca congestiva (ICC), doença coronariana e arritmias, sendo a fibrilação atrial a mais frequente. Nos pacientes em diálise, especialmente hemodiálise, morte súbita de origem cardíaca é responsável por cerca de $25 \%$ dos óbitos. Lembrando que morte súbita é definida como evento inesperado em um paciente sem sintomas ou 1 hora após o aparecimento de sintomas e que estava bem 24 horas antes do óbito. Um fato relevante é que a maioria dos pacientes com DRC não morre de infarto agudo do miocárdio, mas de morte súbita, provavelmente devido a mecanismos não coronarianos que afetam a função cardíaca ${ }^{14,15,16}$

Pacientes em diálise tem um risco 5 a 10 vezes maior de desenvolver acidente vascular cerebral (AVC), sendo a grande maioria do tipo isquêmico (87\%), e 30\% deles ocorrem durante ou imediatamente após a diálise. Os principais fatores de risco para esses eventos são o aumento da pressão arterial sistólica, DM e fibrilação atrial. A doença arterial periférica também é frequente e além da associação com os vários fatores de risco descritos anteriormente, vale destacar os efeitos da qualidade da diálise (menor $\mathrm{Kt} / \mathrm{V}$ ), a presença de hipoalbuminemia, de baixos níveis de paratormônio, hiperfosfatemia, inflamação e desnutrição ${ }^{17,18,19,20}$.

Do ponto de vista anatomopatológico, as principais alterações no sistema cardiovascular, ocorrem nas artérias e no coração. Nas artérias se observam 
espessamento, calcificações e rigidez das paredes. Nos pacientes com DRC, o espessamento das artérias coronárias é mais frequente e intenso que nos indivíduos normais e pode ser diagnosticado com auxílio de ultrassonografia. Dois tipos de calcificações vasculares são observados nesses pacientes, a calcificação da camada média (arteriosclerose ou esclerose de Mönckeberg) e da camada íntima (aterosclerose), essa última é mais intensa e precoce acometendo de 2 a 5 vezes mais pacientes com DRC quando comparados a população geral, pareada por sexo e idade. A calcificação da média é predominantemente não inflamatória, se associa principalmente com idade, $\mathrm{DM}$, tempo em diálise e os distúrbios do metabolismo mineral ${ }^{21}$

No coração, as alterações estruturais mais observadas são a hipertrofia do ventrículo esquerdo resultante da sobrecarga de pressão e/ou volume, estímulos que levam ao estiramento dos cardiomiócitos, aumento do estresse de parede no ventrículo favorecendo a produção e liberação local de angiotensina II, norepinefrina e endotelina, que promovem a expressão de proteínas e hipertrofia dos cardiomiócitos. A progressão da hipertrofia leva a insuficiência cardíaca, o excesso de trabalho dos cardiomiócitos aumenta a apoptose dessas células, e a fibrose intersticial reduz a densidade da rede capilar favorecendo a hipóxia do tecido, mesmo sem obstrução das artérias coronarianas. Além disso, o endurecimento das artérias leva a queda da pressão diastólica e diminuição da perfusão das coronárias, explicando porque pacientes desenvolvem angina mesmo sem obstrução dessas artérias ${ }^{21,22}$.

Ainda que na população geral tenham ocorrido progressos significativos no controle da DCV, tais intervenções e benefícios foram pouco observados em pacientes com DRC.

A inflamação sistêmica e a desnutrição contribuem diretamente para o aumento da mortalidade e de hospitalizações nos pacientes com DRC, além de estarem mutuamente relacionadas ${ }^{22}$. Assim, marcadores do estado nutricional como níveis séricos de creatinina, albumina ${ }^{19}$ e colesterol $^{20}$, apresentam associação com mortalidade, tal como os marcadores de inflamação como a proteína C reativa (PCR) e a Interleucina-6 (IL-6). Níveis de IL-6 associam-se de maneira consistente com morte por todas as causas e por causas 
cardiovasculares $23,24,25,26,27$.

Nos últimos anos, os distúrbios do metabolismo mineral foram incluídos na lista dos fatores de risco que contribuem para aumentar a mortalidade desses pacientes ${ }^{28,29,30}$ e incluem as alterações do cálcio $(\mathrm{Ca})$, fósforo $(\mathrm{P})$, paratormônio (PTH), 25(OH) vitamina $\mathrm{D}$ e do fator de crescimento de fibroblastos 23 (FGF-23) ${ }^{30}$. Recentemente, o estudo COSMOS confirmou não somente associação entre esses distúrbios e maior mortalidade, como também revelou que o controle dos mesmos melhorou a sobrevida dos pacientes, demonstrando que são fatores de risco potencialmente modificáveis ${ }^{31}$.

O Ca desempenha um papel fundamental na contração e no relaxamento da fibra miocárdica. Estudo recente revelou que a hipocalcemia foi um fator preditivo independente de disfunção diastólica do ventrículo esquerdo em pacientes com DRC. ${ }^{32} \mathrm{Em}$ contrapartida, estudo epidemiológico realizado com pacientes em hemodiálise mostrou associação entre níveis elevados de Ca e maior mortalidade por causas cardiovasculares. ${ }^{33}$ Acredita-se que a sobrecarga de Ca decorrente do uso de quelantes de $\mathrm{P}$ contendo cálcio, níveis elevados de cálcio no dialisato, uso de altas doses de calcitriol e análogos que favorecem a hipercalcemia, contribuem para deposição desse elemento no tecido cardíaco e vasos acelerando a CV. Os mecanismos pelos quais o Ca sérico promove CV não estão completamente esclarecidos. Níveis elevados de Ca especialmente nas células musculares lisas podem induzir produção de vesículas e levar tanto a apoptose como necrose dessas células além mineralizar as vesículas. 0 acumulo dessas vesículas e dos corpos apoptóticos leva ao crescimento dos cristais de hidroxiapatita $34,35,36,37,38,39,40,41$

Nos últimos anos, diversos estudos mostraram associação entre $P$ sérico e mortalidade $42,43,44,47$. Os mecanismos envolvidos não são totalmente conhecidos, mas in vitro o $\mathrm{P}$ pode estimular a transformação fenotípica das células musculares lisas da camada média das artérias em osteoblastos-símile e promover a CV45,46,47,48,49,50.

Quanto ao PTH, o sistema cardiovascular (células endoteliais, musculares lisas, cardiomiócitos) expressa receptores para esse hormônio, sugerindo sua participação tanto na regulação normal como nas alterações patológicas. 
Pacientes com hiperparatiroidismo primário e secundário podem desenvolver calcificações das valvas cardíacas, espessamento da aorta, disfunção endotelial e hipertensão arterial aumentando os riscos de morte por DCV51,52,53,54,55.

A vitamina $D$, cujos estoques corporais são avaliados pelos níveis séricos de $25(\mathrm{OH})$ vitamina $\mathrm{D}$, é um importante hormônio para a integridade do esqueleto. Sua deficiência é muito prevalente na população normal, acredita-se que mais de um bilhão de pessoas no mundo tenha deficiência dessa vitamina. Os pacientes com DRC, em todos os estágios não fogem à regra, e a deficiência se associa com várias complicações como por exemplo, piora da função renal naqueles pacientes em tratamento conservador, calcificação vascular, disfunção endotelial, eventos cardiovasculares e mortalidade por causas cardiovasculares ${ }^{56,57,58,59}$.

A conversão de $25(\mathrm{OH})$ vitamina $D$ em vitamina $D$ ativa $(1,25(\mathrm{OH})$ vitamina $\mathrm{D}$ ), ocorre principalmente nos túbulos proximais, e é muito efetiva nos indivíduos normais mesmo diante de deficiência dessa vitamina, o que não ocorre nos pacientes com DRC. A vitamina $D$ ativa exerce suas funções ligando-se a um receptor (VDR) expresso em mais de 30 órgãos, incluindo ossos, intestino, paratireóides, músculo esquelético e cardíaco, entre outros ${ }^{60}$.

A principal função da vitamina $D$ ativa é manter o metabolismo do cálcio e fósforo em associação estreita com o PTH. No entanto, vale ressaltar que também desempenha importante função renocardioprotetora. Assim, nos pacientes com DRC os níveis reduzidos de $25(\mathrm{OH})$ vitamina $D$ dificultam ainda mais a sua conversão no metabólito ativo e se associam a um aumento da mortalidade por diferentes causas entre elas DCV61,62.

Pilz $S$ e cols. realizaram uma meta-análise na qual analisaram estudos observacionais e demonstraram uma relação inversa entre os níveis séricos de $25(\mathrm{OH})$ vitamina $\mathrm{D}$ e mortalidade por todas as causas ${ }^{63}$.

O FGF-23 é um hormônio que regula o metabolismo do fósforo. Trata-se de uma proteína produzida principalmente pelos osteócitos composto de 251 aminoácidos e um peso molecular de $32 \mathrm{kDa}^{64}$. Seu principal órgão alvo é o rim, onde diminui a reabsorção de fósforo no túbulo proximal e inibe a enzima 
1- $\alpha$ hidroxilase, diminuindo a produção da vitamina $D$ ativa, além de facilitar sua degradação65,66,67,68,69. Nos estágios iniciais da doença renal, o aumento dos níveis séricos do FGF-23 parece ser o primeiro marcador das alterações do metabolismo mineral e o pivô na fisiopatologia desses distúrbios que leva tanto as doenças ósseas como complicações cardiovasculares, dentre elas as calcificações vasculares ${ }^{70,71}$. O aumento dos níveis séricos desse hormônio precede o do PTH e nos estágios finais da doença renal pode alcançar níveis elevados de 100 a 1000 vezes os valores normais ${ }^{72,73}$.

O início do tratamento dialítico é marcado por elevada morbidade e mortalidade. Nos primeiros 120 dias de diálise a mortalidade pode atingir até $40 \%$ dos pacientes, sendo influenciada por inúmeros fatores, especialmente pelos cuidados que esses pacientes receberam no período da pré-diálise.

Muitos países, inclusive o Brasil, recomendam o encaminhamento precoce de pacientes com doença renal (clearance de creatinina menor que 60 $\mathrm{mL} / \mathrm{min} / 1,73 \mathrm{~m}^{2}$ ou proteinúria) para seguimento com nefrologista, pois essa conduta diminui a mortalidade dos pacientes, especialmente daqueles em fases avançadas da doença ${ }^{74,75,76,77,78}$

No nosso meio poucos estudos avaliaram as características clinicas e os fatores de risco dos pacientes incidentes em diálise, que será o objetivo deste estudo. 


\section{OBJETIVO}

O objetivo desse estudo foi avaliar as características clínicas, bioquímicas, fatores de risco tradicionais e ligados aos distúrbios do metabolismo mineral associados à mortalidade, em pacientes com doença renal crônica, incidentes em diálise. 


\section{PACIENTES E MÉTODOS}

\subsection{Delineamento}

Estudo de coorte observacional prospectivo, realizado com pacientes com DRC incidentes em diálise.

\subsection{Sujeito da Pesquisa}

O estudo foi conduzido em pacientes admitidos no Serviço de Emergência do Hospital das Clinicas, no período de 2006 a 2012. Esses pacientes apresentavam sinais e sintomas de uremia além de exames bioquímicos que confirmavam a insuficiência renal e a necessidade imediata de diálise.

Após o atendimento na emergência, os pacientes foram encaminhados para o terceiro turno do Serviço de Diálise do Hospital das Clínicas, onde permaneciam em tratamento dialítico até estabilização do quadro clinico sendo então, transferidos para centros de diálise mais próximos de suas residências.

\subsection{Critérios de inclusão}

Foram incluídos todos os pacientes admitidos no serviço de emergência com sinais e sintomas clínicos de uremia, alterações bioquímicas, e necessidade imediata de diálise

\subsection{Critérios de exclusão}

Os critérios de exclusão foram: pacientes com idade inferior a 18 anos, em uso de vitamina $D$, transplantados renais atendidos por perda aguda ou 
crônica do enxerto, em tratamento dialítico (diálise peritoneal ou hemodiálise) atendidos na urgência por intercorrências ligadas ao tratamento e pacientes com insuficiência renal mas que durante a internação recuperaram total ou parcialmente a função renal.

\subsection{Aspectos éticos}

O estudo foi conduzido de acordo com os padrões éticos da Declaração de Helsinki. O protocolo foi aprovado pelos Comitês Científico e de Ética em Pesquisa do Hospital das Clínicas da Faculdade de Medicina da Universidade de São Paulo sob o número CAAE 45163715.4.0000.0068.

\subsection{Casuística}

Entre 2006 e 2012, 444 pacientes com insuficiência renal e indicação imediata de diálise foram atendidos no Serviço de Emergência do Hospital das Clínicas da USP e 424 preencheram os critérios de inclusão. Vinte pacientes foram excluídos, pois três tinham menos de 18 anos, quatro usavam regularmente vitamina $D$, quatro eram transplantados renais, três já dialisavam e seis recuperaram a função renal total ou parcialmente.

\subsection{Parâmetros clínicos avaliados}

Os parâmetros clínicos idade, sexo, raça, etiologia da doença renal, presença e tipo de via de acesso para tratamento dialítico, principais fatores de risco e medicações usadas regularmente foram obtidos do prontuário clinico do Serviço de Emergência.

Usamos uma ficha padronizada (Apêndice - protocolo clínico) com questões pré-estabelecidas, para obter informações dos prontuários das Unidades de Diálise (locais para os quais os pacientes foram encaminhados) e 
dos diversos ambulatórios e enfermarias do Hospital das Clínicas e do Instituto do Coração (INCOR), para os quais os pacientes eram encaminhados dependendo das complicações clínicas ocorridas ao longo do seguimento. Registramos todas as intercorrências do primeiro ano de diálise.

Quando os prontuários eram incompletos, as informações foram complementadas diretamente com os profissionais que trabalhavam nas clínicas de diálise, com os pacientes ou seus familiares através de ligações telefônicas.

Os dados foram anotados e arquivados respeitando-se o sigilo das informações.

Essas informações permitiram confirmar os fatores de risco detectados no atendimento na emergência, assim como identificar as complicações, as medicações utilizadas e as hospitalizações que ocorreram durante o primeiro ano de diálise.

Consideramos como tabagistas, apenas os pacientes com história atual de tabagismo. Para estabelecer que a etiologia da doença renal fosse hipertensão arterial, consideramos as informações do prontuário, o uso de medicação anti-hipertensiva. $\mathrm{Na}$ admissão, os pacientes que apresentavam PA sistólica maior ou igual a $140 \mathrm{mmHg}$ e diastólica maior ou igual a $90 \mathrm{mmHg}$, obtida da anotação antes da primeira sessão de hemodiálise, independente do paciente estar ou não recebendo medicação anti-hipertensiva, foram considerados hipertensos.

Para o diagnóstico de diabetes mellitus usamos informações do prontuário, resultados dos exames laboratoriais e uso de medicações como hipoglicemiante oral e ou insulina.

Pacientes com níveis séricos de colesterol total maior ou igual a 200 $\mathrm{mg} / \mathrm{dL}$ ou LDL acima de $100 \mathrm{mg} / \mathrm{dL}$ e triglicérides maiores que $150 \mathrm{mg} / \mathrm{dL}$ ou usando medicações hipolipemiantes foram considerados dislipidêmicos.

Pacientes com história de angina, infarto agudo do miocárdio, angioplastia ou revascularização do miocárdio foram considerados como portadores de doença cardíaca isquêmica (DCl). Aqueles com história pregressa de acidente 
vascular cerebral, ataque isquêmico transitório, ou que tinham se submetido a endarterectomia de carótida foram classificados como portadores de doença cerebrovascular (AVC).

Quando, no prontuário, havia relato de dispneia, edema periférico, estase jugular, hepatomegalia, congestão pulmonar detectada no exame físico ou na radiografia de tórax, limitação para a realização das atividades físicas e uso de medicações especificas, os pacientes receberam o diagnostico de insuficiência cardíaca congestiva (ICC). Aqueles pacientes em uso de medicações antiarrítmicas, eletrocardiograma com alterações no ritmo e na frequência foram classificados como portadores de arritmia cardíaca.

Já os pacientes com história de claudicação, amputação ou ulceração por isquemia de algum membro ou que foram submetidos à revascularização periférica foram diagnosticados como portadores de doença arterial periférica (DAP).

O conjunto de DCI, AVC, ICC e DAP constituiu o que chamamos de DCV.

As causas de óbito foram obtidas do atestado de óbito, ou da anotação no prontuário do Hospital das Clinicas ou do centro de diálise.

\subsection{Análise laboratorial}

As dosagens bioquímicas foram realizadas no Laboratório Central do Instituto Central do Hospital das Clínicas de São Paulo. Foram coletadas amostras de sangue antes da primeira sessão de diálise, em uma única ocasião. Analisamos o hemograma (automatizado/microscopia/coloração panóptica), os níveis séricos de uréia (VR: 10 a $50 \mathrm{mg} / \mathrm{dL}$ - cinético automatizado), creatinina (VR: 0,70 a $1,20 \mathrm{mg} / \mathrm{dL}$ - colorimétrico cinético), albumina (VR: 3,4 a 4,8 $\mathrm{g} / \mathrm{dL}$ - colorimétrico automatizado), proteína $\mathrm{C}$ reativa (VR: inferior a 5,0 mg/L - imunoturbidimétrico), cálcio iônico (VR: 4,6 a 5,3 $\mathrm{mg} / \mathrm{dL}$ - eletrodo íon seletivo), fósforo (VR: 2,7 a $4,5 \mathrm{mg} / \mathrm{dL}$ - enzimático colorimétrico automatizado), colesterol total (VR: inferior a $200 \mathrm{mg} / \mathrm{dL}$ enzimático colorimétrico automatizado), LDL (VR: inferior a $130 \mathrm{mg} / \mathrm{dL}$ - 
cinético automatizado), HDL (VR: superior a $60 \mathrm{mg} / \mathrm{dL}$ - enzimático colorimétrico automatizado), triglicérides (inferior a $150 \mathrm{mg} / \mathrm{dL}$ - enzimático colorimétrico automatizado), glicose (VR: 70 a $99 \mathrm{mg} / \mathrm{dL}$ - hexoquinase), ferro (VR: 59 a $158 \mu \mathrm{g} / \mathrm{dL}$ - colorimétrico automatizado), ferritina (VR: 30 a 400 $\mathrm{ng} / \mathrm{mL}$ - eletroquimioluminescência), índice de saturação de ferro (VR: 20 a 40\%, cálculo); fosfatase alcalina (VR: 40 a $129 \mathrm{U} / \mathrm{L}$ - cinético automatizado). Amostras de plasma ou soro foram congeladas para posterior dosagem de PTH (VR: 16 a $87 \mathrm{pg} / \mathrm{mL}$ - eletroquimioluminométrico), 25(OH) vitamina D (VR: 30 a $100 \mathrm{ng} / \mathrm{mL}$ - DiaSorin Inc., Stillwater, MN, Estados Unidos), FGF-23 (VR: inferior a $53 \mathrm{pg} / \mathrm{mL}$ - FGF-23 intacto ELISA, Kainos, Japão) e pró-peptídeo natriurético cerebral (NT-pró-BNP) (VR: inferior a $100 \mathrm{pg} / \mathrm{mL}$ - imunoensaio quimioluminescente, Roche, Suiça).

\subsection{Análise estatística}

Os dados foram analisados quanto à distribuição amostral visando verificar a normalidade. Quando os parâmetros não apresentavam distribuição normal, os resultados foram expressos em mediana (mínimo; máximo), sendo a comparação entre grupos feita pelo teste de Mann Whitney. Variáveis categóricas foram apresentadas em valor absoluto e percentagem e comparadas com teste de Qui-quadrado ou Fisher, apropriadamente. A sobrevida dos pacientes foi analisada através de curva de Kaplan-Meier, sendo a diferença entre fatores avaliada através de teste de log-rank. Análise de regressão de Cox, tipo Backward Conditional foi utilizada para avaliar em conjunto fatores que influenciaram a sobrevida. Considerou-se significante valores de probabilidade de erro tipo I inferiores a $5 \%$. As análises foram obtidas com o software SPSS versão 20.0. 


\section{RESULTADOS}

4.1. Características clínicas e principais fatores de risco detectados nos pacientes admitidos na Emergência

$\mathrm{Na}$ tabela 1 descrevemos as características clínicas dos pacientes e os principais fatores de risco relatados no prontuário da Emergência.

A média de idade foi de $50 \pm 18$ anos; $58,7 \%$ eram homens e $69,1 \%$ brancos. A HAS foi a principal etiologia da doença renal primária $(31,8 \%)$ seguida de DM $(29,5 \%)$.

Os principais fatores de risco descritos foram tabagismo (19,6\%), dislipidemia $(48,8 \%)$, ICC $(19,8 \%)$, DCl, especialmente isquemia coronariana, $(13,4 \%)$ e DAP $(7,8 \%)$.

No exame físico de admissão $95,8 \%$ dos pacientes estavam hipertensos e $86,8 \%$ usavam hipotensores. A média da pressão arterial sistólica foi de $152 \pm$ $24 \mathrm{mmHg}$ e diastólica de $82 \pm 15 \mathrm{mmHg}$. 
Tabela 1. Características clínicas e principais fatores de risco dos pacientes admitidos na Emergência

\begin{tabular}{lc} 
Variável & Total $(\mathbf{n}=\mathbf{4 2 4})$ \\
Idade (anos) & $50 \pm 18$ \\
Raça (Branco) $n, \%$ & $293(69,1)$ \\
Sexo (Masculino) $n$,\% & $249(58,7)$ \\
Etiologia DRC $n$, \% & \\
$\quad$ Hipertensão arterial & $135(31,8)$ \\
$\quad$ Diabetes mellitus & $125(29,5)$ \\
Glomerulonefrite crônica & $53(12,5)$ \\
$\quad$ Doença renal policística do adulto & $12(2,8)$ \\
$\quad$ Outras & $99(23,3)$ \\
Fatores de risco n, \% & \\
$\quad$ Tabagismo & $83(19,6)$ \\
Dislipidemia & $207(48,8)$ \\
Insuficiência cardíaca & $84(19,8)$ \\
Insuficiência coronariana & $57(13,4)$ \\
Insuficiência vascular periférica & $33(7,8)$ \\
Hipertensão arterial & $406(96)$ \\
Diabetes mellitus & $150(35)$ \\
PA pré-diálise & \\
PA sistólica, mmHg & $152 \pm 24$ \\
PA diastólica, mmHg & $82 \pm 15$ \\
Seguimento (dias) & $424(10 ; 365)$ \\
Óbito n,\% & $60(14,1 \%)$ \\
\hline Res &
\end{tabular}

Resultados expressos em média \pm DP ou mediana (min, max); DRC: doença renal crônica; PA: Pressão arterial. 
As principais medicações usadas pelos pacientes na admissão estão descritas na tabela 2. A maior parte usava hipotensores, especialmente bloqueadores de canal de cálcio e betabloqueadores. Porém, uma parte considerável dos diabéticos $(32,8 \%)$ e dos dislipidêmicos (48,7\%) não usava medicações específicas.

Tabela 2. Principais medicações usadas pelos pacientes na admissão

\begin{tabular}{|c|c|c|}
\hline Medicação & $\mathbf{n}$ & $\%$ \\
\hline IECA/BRA & 100 & 23,6 \\
\hline Bloqueador de canal de cálcio & 281 & 66,3 \\
\hline Betabloqueadores & 204 & 48,1 \\
\hline Outros hipotensores & 199 & 46,9 \\
\hline Antiarrítmicos & 26 & 6,1 \\
\hline Anti-agregante plaquetário & 126 & 29,7 \\
\hline Hipoglicemiantes orais ou insulina & 84 & 19,8 \\
\hline Estatinas & 101 & 23,8 \\
\hline $\mathrm{CaCO}_{3}$ & 85 & 20 \\
\hline Sevelamer & 39 & 9,2 \\
\hline
\end{tabular}




\subsection{Acesso vascular}

A maioria dos pacientes não tinha acesso vascular na admissão e necessitou de implante de cateter temporário de duplo lúmen (CDL; 89\%). Somente 16 deles (4\%) tinham fístula arteriovenosa (FAV) (Figura 1). Ao final do primeiro ano $75 \%$ dos pacientes dialisavam por FAV (Figura 2).

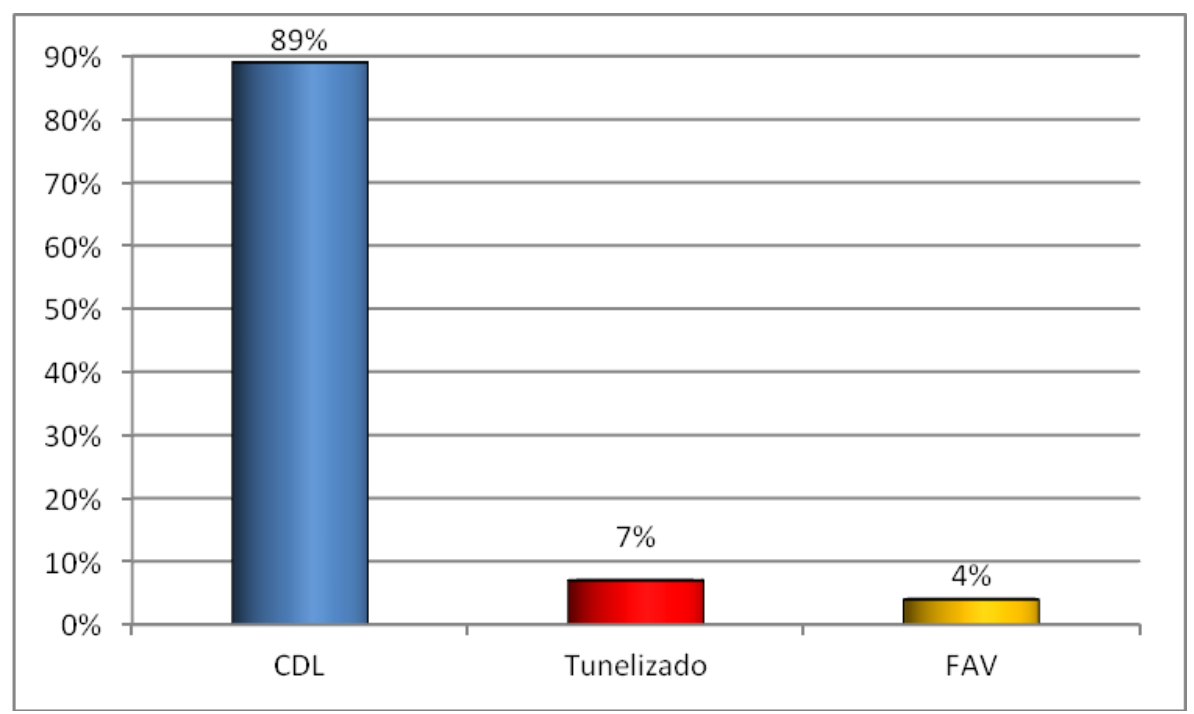

Figura 1. Acesso vascular na admissão.

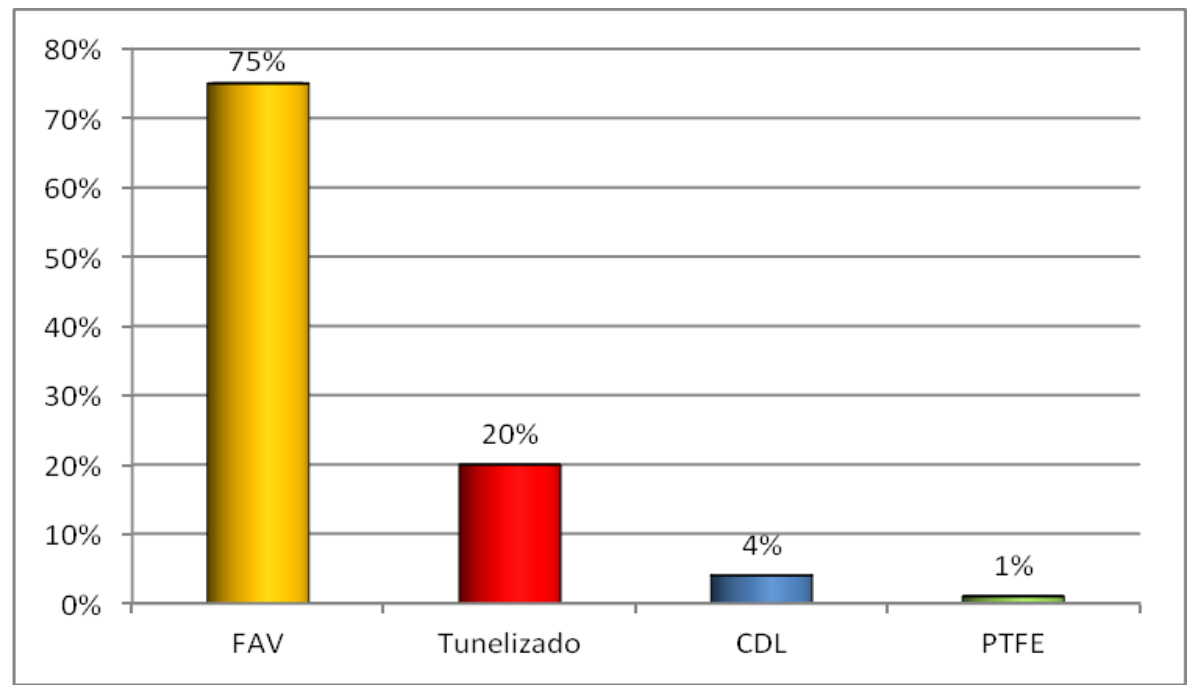

Figura 2. Acesso vascular ao fim do primeiro ano. 


\subsection{Características laboratoriais}

A tabela 3 resume os dados laboratoriais dos pacientes na admissão.

Em $83,7 \%$ dos pacientes, a hemoglobina sérica era inferior a $11 \mathrm{~g} / \mathrm{dL}$ e $33,5 \%$ apresentavam albumina inferior a $3,5 \mathrm{~g} / \mathrm{dL}$.

Quanto ao perfil lipídico $70,9 \%$ dos pacientes tinham colesterol total menor que $200 \mathrm{mg} / \mathrm{dL}$ e em $54,8 \%$ a fração LDL era menor que $100 \mathrm{mg} / \mathrm{dL}$, além dos níveis de triglicérides serem inferiores a $150 \mathrm{mg} / \mathrm{dL}$ em $51,8 \%$.

Entre os pacientes com colesterol menor que $200 \mathrm{mg} / \mathrm{dL}, 38 \%$ recebiam tratamento com estatinas enquanto $24 \%$ daqueles com colesterol maior que $200 \mathrm{mg} / \mathrm{dL}$ também usavam esta medicação $(p=0,064)$. Os níveis de glicemia anotados no prontuário não obrigatoriamente correspondiam ao estado de jejum, assim valores maiores que $125 \mathrm{mg} / \mathrm{dL}$ foram detectados em $28 \%$ dos pacientes e superiores a $200 \mathrm{mg} / \mathrm{dL}$ em $10 \%$.

Em relação ao metabolismo do ferro, a ferritina era menor que $100 \mathrm{ng} / \mathrm{mL}$ em $10,26 \%$ e o índice de saturação de ferro (ISAT) menor que $20 \%$ em $44,47 \%$.

A grande maioria dos pacientes $(79,9 \%)$ tinha níveis elevados de PCR (superior a $5,0 \mathrm{mg} / \mathrm{L}$ ).

A análise dos marcadores do metabolismo mineral revelou hipocalcemia (cálcio iônico menor que 4,6 mg/dL) em 48,1\%, e hiperfosfatemia (fósforo superior a $5,5 \mathrm{mg} / \mathrm{dL}$ ) em $74,2 \%$ dos pacientes. A hipovitaminose $D[25(\mathrm{OH})$ vitamina $D$ menor que $30 \mathrm{ng} / \mathrm{mL}$ ] foi diagnosticada em 95,1\%. Hiperparatireoidismo secundário (PTH maior que $65 \mathrm{pg} / \mathrm{mL}$ ) foi observado em $69,1 \%$ dos pacientes. Quanto aos níveis séricos de FGF-23, encontramos uma grande variabilidade, sendo a mediana de $1927,5 \mathrm{pg} / \mathrm{mL}$ (1913 a 37.721 $\mathrm{pg} / \mathrm{mL}$ ). Somente $0,47 \%$ dos pacientes tinham níveis séricos de FGF-23 normais (FGF-23 inferior a $53 \mathrm{pg} / \mathrm{mL}$ ).

O NT-pró-BNP foi dosado em 399 pacientes e somente oito tinham níveis séricos dentro da faixa de referência (até $125 \mathrm{pg} / \mathrm{mL}$ ). Como pacientes em diálise e com ICC apresentam habitualmente níveis mais elevados de NT-pró- 
BNP (até $6.000 \mathrm{pg} / \mathrm{mL}$ ), também utilizamos este valor como outro ponto de corte e detectamos que $41,3 \%$ deles apresentavam níveis tão elevados. Destes pacientes com NT-pró-BNP acima de $6.000 \mathrm{pg} / \mathrm{mL}$, encontramos um percentual maior de portadores de ICC (47,6 vs. $36,8 \%$, respectivamente; $p=0,006)$.

\section{Tabela 3. Características laboratoriais dos pacientes na admissão}

\begin{tabular}{lc}
\multicolumn{1}{c}{ Variável } & Total $(\mathbf{n}=\mathbf{4 2 4})$ \\
Creatinina, mg/dL & $8,78(3,02 ; 35,44)$ \\
Uréia, mg/dL & $228,7(80 ; 545)$ \\
Hemoglobina, g/dL & $8,8(3,1 ; 17,5)$ \\
Hematócrito, \% & $27,2(10,2 ; 60,3)$ \\
Cálcio iônico, mg/dL & $4,60(1,2 ; 5,9)$ \\
Fósforo, mg/dL & $6,75(1,8 ; 18,4)$ \\
Fosfatase Alcalina, U/L & $90(15 ; 790)$ \\
25 (OH) vitamina D, $\mathrm{ng} / \mathrm{mL}$ & $12,3(4 ; 46,8)$ \\
Paratormônio, pg/mL & $165(3 ; 4287)$ \\
FGF- 23, pg/mL & $1927,2(19,1 ; 37721)$ \\
Triglicérides, mg/dL & $147(16 ; 889)$ \\
Colesterol total, mg/dL & $175(69 ; 472)$ \\
LDL colesterol , mg/dL & $95,5(15 ; 483)$ \\
HDL colesterol, mg/dL & $43(11 ; 126)$ \\
Albumina, g/dL & $3,3(1,2 ; 5,1)$ \\
Proteína-C Reativa, mg/L & $14,9(0,2 ; 529)$ \\
Glicose, mg/dL & $89(55 ; 482)$ \\
Ferro, $\mu$ g/dL & $51(5 ; 266)$ \\
Ferritina, $\mathrm{ng} / \mathrm{mL}$ & $336,3(15,1 ; 7163)$ \\
ISAT, \% & $21,8(1,93 ; 226,1)$ \\
NT-pró-BNP, pg/mL & $4793(5 ; 35000)$ \\
& \\
\hline
\end{tabular}

Resultados expressos em mediana (mínimo; máximo). ISAT: índice de saturação do ferro. 
Ao final do primeiro ano, 60 pacientes foram a óbito. A mediana do tempo de seguimento desses pacientes foi de 188 dias. Na Tabela 4 comparamos os pacientes sobreviventes e não-sobreviventes, quanto às características clínicas, fatores de risco e tipo de via de acesso para diálise quando do atendimento na urgência. Comparamos ainda o tipo de via de acesso ao final do seguimento. Os que faleceram eram mais idosos, apresentavam ICC, e a maioria permanecia sem FAV.

\section{Tabela 4. Comparação das características clínicas e fatores de risco detectados na admissão entre pacientes sobreviventes e não- sobreviventes}

\begin{tabular}{|c|c|c|c|c|}
\hline Variável & $\begin{array}{c}\text { Total } \\
\mathrm{N}=424\end{array}$ & $\begin{array}{l}\text { Sobreviventes } \\
\qquad N=364\end{array}$ & $\begin{array}{c}\text { Não } \\
\text { Sobreviventes } \\
N=60\end{array}$ & $\mathbf{p}$ \\
\hline Idade (anos) & $50 \pm 18$ & $48 \pm 17$ & $59 \pm 18$ & $<0,0001$ \\
\hline Raça (Branco) & $293(69,1)$ & $25169)$ & $42(70)$ & 0,871 \\
\hline Sexo (Masculino) & $249(58,7)$ & $218(60)$ & $31(52)$ & 0,231 \\
\hline \multicolumn{5}{|l|}{ Etiologia DRC } \\
\hline Hipertensão arterial & $135(31,8)$ & $117(32)$ & $18(30)$ & \multirow{5}{*}{0,171} \\
\hline Diabetes mellitus & $125(29,5)$ & $104(29)$ & $21(35)$ & \\
\hline Glomerulonefrite crônica & $53(12,5)$ & $49(13)$ & $4(7)$ & \\
\hline Doença renal policística do adulto & $12(2,8)$ & $11(3)$ & $1(2)$ & \\
\hline Outras & $99(23,3)$ & $83(23)$ & $16(27)$ & \\
\hline \multicolumn{5}{|l|}{ Fatores de risco } \\
\hline Tabagismo & $83(19,6)$ & $69(19)$ & $14(23)$ & 0,428 \\
\hline Dislipidemia & $207(48,8)$ & $181(50)$ & $26(43)$ & 0,359 \\
\hline Insuficiência cardíaca & $84(19,8)$ & $66(18)$ & $18(30)$ & 0,033 \\
\hline Insuficiência coronariana & $57(13,4)$ & $50(14)$ & $7(12)$ & 0,663 \\
\hline Insuficiência vascular periférica & $33(7,8)$ & $28(8)$ & $5(8)$ & 0,864 \\
\hline Hipertensão arterial & $406(96)$ & $349(96)$ & $57(95)$ & 0,754 \\
\hline Diabetes mellitus & $150(35)$ & $126(35)$ & $24(40)$ & 0,419 \\
\hline \multicolumn{5}{|l|}{ 10 Acesso vascular } \\
\hline CDL & $379(89)$ & $322(88)$ & $57(95)$ & \multirow{3}{*}{0,313} \\
\hline FAV & $16(4,0)$ & $15(4)$ & $1(2)$ & \\
\hline Cateter tunelizado & $29(7,0)$ & $27(7)$ & $2(3)$ & \\
\hline \multicolumn{5}{|l|}{ Acesso vascular final seguimento } \\
\hline CDL & $18(4)$ & $8(2)$ & $10(17)$ & \multirow{4}{*}{$<0,0001$} \\
\hline FAV & $318(75)$ & $289(79)$ & $29(48)$ & \\
\hline Cateter tunelizado & $85(20)$ & $65(18)$ & $20(33)$ & \\
\hline PTFE & $3(1)$ & $2(1)$ & $1(2)$ & \\
\hline Tempo seguimento (Dias) & - & $365(76 ; 365)$ & $188(10 ; 363)$ & $<0,0001$ \\
\hline
\end{tabular}

Resultados expressos em média $\pm D P, n(\%)$ ou mediana (mínimo, máximo); CDL: catéter duplo lúmen; FAV: fistula arteriovenosa; PTFE: enxerto arteriovenoso sintético. 


\subsection{Comparações dos resultados laboratoriais na admissão entre pacientes sobreviventes e não-sobreviventes}

$\mathrm{Na}$ Tabela 5, comparamos os resultados laboratoriais dos pacientes sobreviventes ou não-sobreviventes na admissão.

Os não-sobreviventes tinham níveis menores de uréia, creatinina, colesterol total, triglicérides e ferro sérico, enquanto os níveis de PCR eram mais elevados. Quanto aos marcadores do metabolismo mineral, observamos que os níveis séricos de cálcio e fosfatase alcalina eram maiores e os de fósforo menores no grupo de não-sobreviventes.

Tabela 5. Comparação dos resultados laboratoriais detectadas na admissão entre pacientes sobreviventes e não-sobreviventes

\begin{tabular}{|c|c|c|c|c|}
\hline Variável & $\begin{array}{c}\text { Total } \\
n=424\end{array}$ & $\begin{array}{l}\text { Sobreviventes } \\
\qquad n=364\end{array}$ & $\begin{array}{c}\text { Não-Sobreviventes } \\
n=60\end{array}$ & p \\
\hline Creatinina, mg/dL & $8,78(3,02 ; 35,44)$ & $9,1(3,4 ; 35,4)$ & $7,8(3,0 ; 24,1)$ & 0,014 \\
\hline Ureia, mg/dL & $228,7(80 ; 545)$ & $215,5(87 ; 545)$ & $190,5(80 ; 420)$ & 0,010 \\
\hline Hemoglobina, g/dL & $8,8(3,1 ; 17,5)$ & $8,8(3,1 ; 17,5)$ & $8,4(5,3 ; 15,3)$ & 0,220 \\
\hline Hematócrito, \% & $27,2(10,2 ; 60,3)$ & $27,3(10,2 ; 60,3)$ & $26,3(17,2 ; 44)$ & 0,459 \\
\hline Cálcio iônico, mg/dL & $4,60(1,2 ; 5,9)$ & $4,44 \pm 0,62$ & $4,68 \pm 0,46$ & 0,005 \\
\hline Fósforo, mg/dL & $6,7(1,8 ; 18,4)$ & $7,4 \pm 3,5$ & $6,2 \pm 1,9$ & 0,011 \\
\hline Fosfatase alcalina, U/L & $90(15 ; 790)$ & $88(15 ; 790)$ & $100(34 ; 749)$ & 0,029 \\
\hline 25(OH) vitamina $\mathrm{D}, \mathrm{ng} / \mathrm{mL}$ & $12,3(4 ; 46,8)$ & $12,3(4 ; 46,8)$ & $12,4(4 ; 38,3)$ & 0,346 \\
\hline Paratormônio, pg/mL & $165(3 ; 4287)$ & $168(3 ; 4123)$ & $146(3 ; 4287)$ & 0,484 \\
\hline FGF- 23, pg/mL & $1927(19,1 ; 37721)$ & $1960(19,1 ; 37721)$ & $1796(77 ; 21093)$ & 0,380 \\
\hline Triglicérides, mg/dL & $147(16 ; 889)$ & $151(36 ; 889)$ & $127(16 ; 374)$ & 0,031 \\
\hline Colesterol total, $\mathrm{mg} / \mathrm{dL}$ & $175(69 ; 472)$ & $177(69 ; 472)$ & $156(80,322)$ & 0,050 \\
\hline LDL colesterol, mg/dL & $95,5(15 ; 483)$ & $96(15 ; 483)$ & $93(26 ; 246)$ & 0,296 \\
\hline HDL colesterol, mg/dL & $43(11 ; 126)$ & $43(11 ; 126)$ & $42(11 ; 92)$ & 0,965 \\
\hline Albumina, $\mathrm{g} / \mathrm{dL}$ & $3,3(1,2 ; 5,1)$ & $3,26 \pm 0,7$ & $3,17 \pm 0,63$ & 0,323 \\
\hline Proteína- C Reativa, mg/L & $14,9(0,2 ; 529)$ & $13,6(0,1 ; 529)$ & $32,2(0,15 ; 254)$ & 0,012 \\
\hline Glicose, mg/dL & $89(55 ; 482)$ & $89(55 ; 482)$ & $90(66 ; 404)$ & 0,807 \\
\hline Ferro, $\mu \mathrm{g} / \mathrm{dL}$ & $51(5 ; 266)$ & $53(5 ; 266)$ & $43(12 ; 176)$ & 0,012 \\
\hline Ferritina, $\mathrm{ng} / \mathrm{mL}$ & $336,3(15,1 ; 7163)$ & $346(15 ; 7163)$ & $272(22,6 ; 2209)$ & 0,102 \\
\hline ISAT, \% & $21,8(1,93 ; 226,1)$ & $22,1(1,9 ; 226,1)$ & $19,0(5,1 ; 88,9)$ & 0,178 \\
\hline NT-pró-BNP , pg/mL & $4793(5 ; 35000)$ & $4793(5 ; 35000)$ & $4900(183 ; 35000)$ & 0,569 \\
\hline
\end{tabular}

Resultados expressos em mediana (mínimo; máximo); ISAT: índice de saturação do ferro. 


\subsection{Principais medicações empregadas pelos pacientes sobreviventes e} não-sobreviventes durante o seguimento

$\mathrm{Na}$ tabela 6 descrevemos os principais medicamentos usados pelos pacientes ao longo do seguimento. Drogas dos grupos IECA/BRA e antiagregante plaquetário foram mais usadas pelos não-sobreviventes, e o sevelamer pelos sobreviventes.

Tabela 6. Principais medicações empregadas ao longo do seguimento entre pacientes sobreviventes e não-sobreviventes

\begin{tabular}{lccc}
\multicolumn{1}{c}{ Variável $\mathbf{n , ~ \% ~}$} & $\begin{array}{c}\text { Sobreviventes } \\
\mathbf{N}=\mathbf{3 6 4}\end{array}$ & $\begin{array}{c}\text { Não } \\
\text { Sobreviventes } \\
\mathbf{N}=\mathbf{6 0}\end{array}$ & $\mathbf{p ~}$ \\
Hipotensor & $309(85)$ & $50(83)$ & 0,756 \\
IECA / BRA & $84(23,1)$ & $21(35)$ & $\mathbf{0 , 0 4 7}$ \\
Bloqueador de canal de cálcio & $241(66,2)$ & $33(55)$ & 0,092 \\
Betabloqueador & $177(49)$ & $26(43$ & 0,447 \\
Outros hipotensores & $167(45,9)$ & $30(50)$ & 0,476 \\
Antiarrítmico & $22(6)$ & $3(5)$ & 0,75 \\
Anti-agregante plaquetário & $120(33)$ & $27(45)$ & $\mathbf{0 , 0 2 9}$ \\
Hipoglicemiante oral ou insulina & $72(19,8)$ & $18(30)$ & 0,073 \\
Estatina & $100(27,5)$ & $19(31,7)$ & 0,503 \\
CaCO 3 & $76(57)$ & $9(15)$ & 0,292 \\
Sevelamer & $208(57)$ & $24(42)$ & $\mathbf{0 , 0 2 6}$
\end{tabular}

IECA: Inibidor de conversão da angiotensina, BRA: bloqueador de receptor da angiotensina, $\mathrm{CaCO}_{3}$ : carbonato de cálcio 
4.6. Principais complicações que ocorreram nos pacientes sobreviventes e não-sobreviventes ao longo do seguimento

As infecções do acesso vascular $(92 \% ; p<0,04)$ seguidas de infecções pulmonares $(80 \% ; p<0,017)$ foram mais frequentes nos pacientes que não sobreviveram, conforme demonstrado na Figura 4.

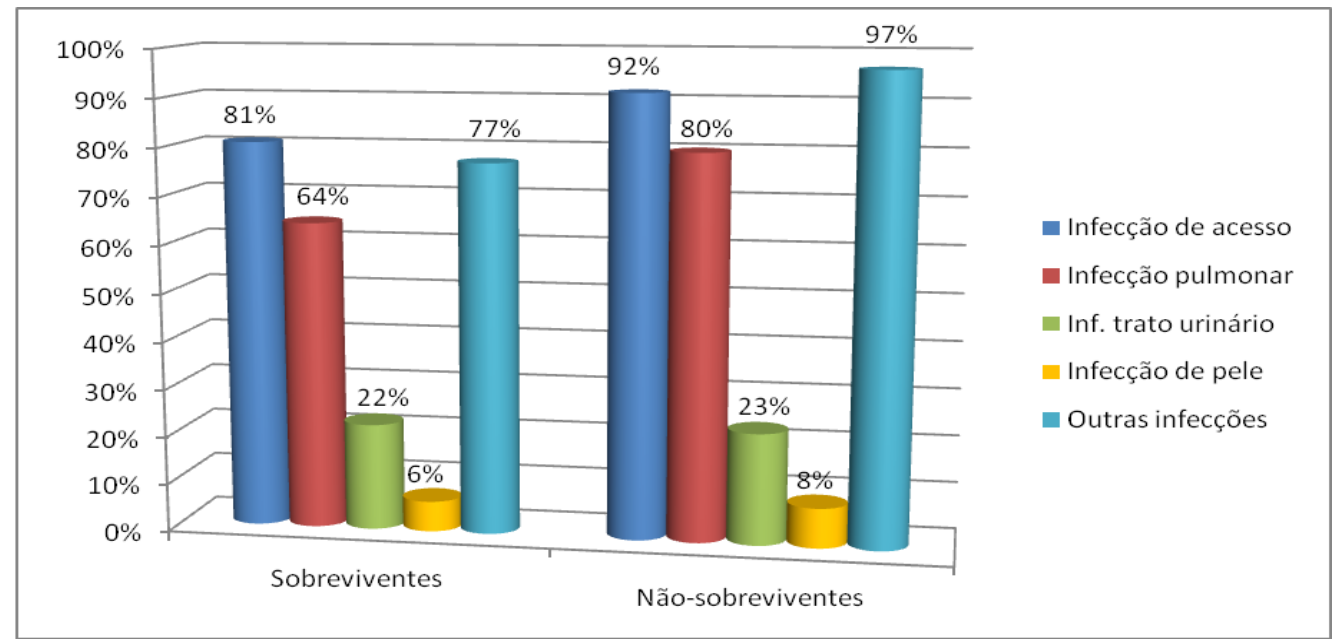

Figura 3. Infecções ocorridas ao longo do seguimento nos pacientes sobreviventes e não-sobreviventes

Nos pacientes não-sobreviventes encontramos mais antecedentes de ICC, arritmias e DCI, além de DVP (Figura 5).

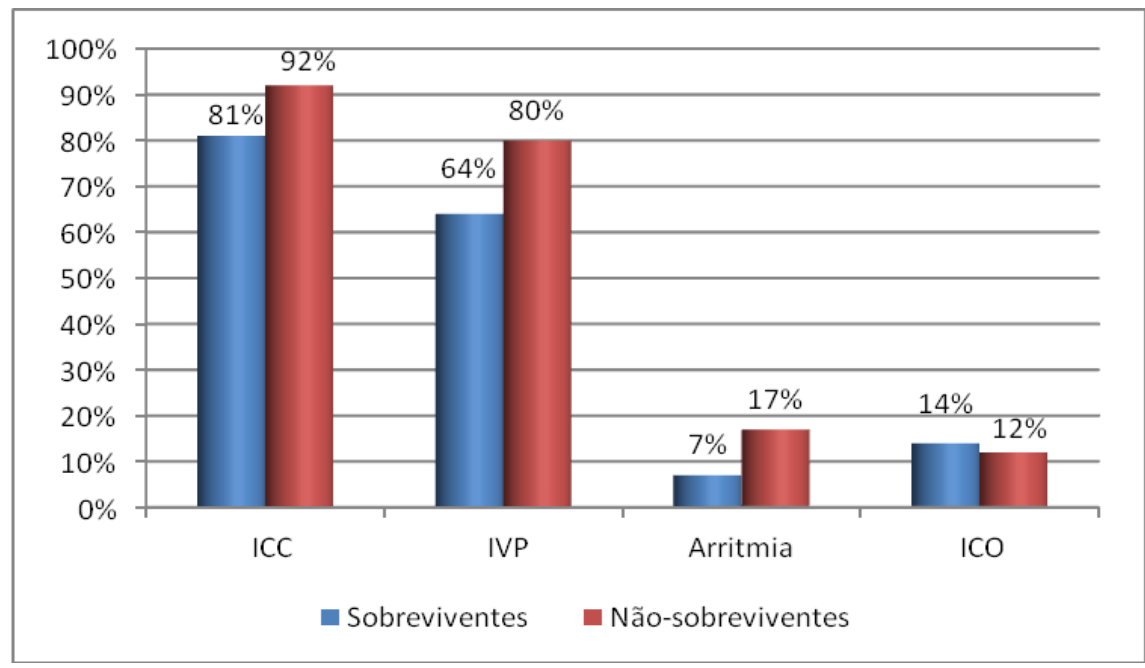

Figura 4. Antecedentes de eventos cardiovasculares ocorridos ao longo do seguimento nos pacientes sobreviventes e não-sobreviventes 
Durante o primeiro ano de diálise houve 112 hospitalizações e a taxa de internação foi 264/1000 pacientes, sendo maior entre os não-sobreviventes (47 vs. $23 \% p=0,0001$ ).

Ao analisarmos as curvas de sobrevida detectamos que antecedentes de ICC influenciavam a expectativa de vida dos pacientes (Figura 6). A média de sobrevida foi de $326 \pm 4$ vs. $344 \pm 10$ dias entre pacientes com e sem ICC, respectivamente. Para evitar um viés analítico, decidimos reavaliar os pacientes sobreviventes e não-sobreviventes de acordo com a presença ou não de ICC.

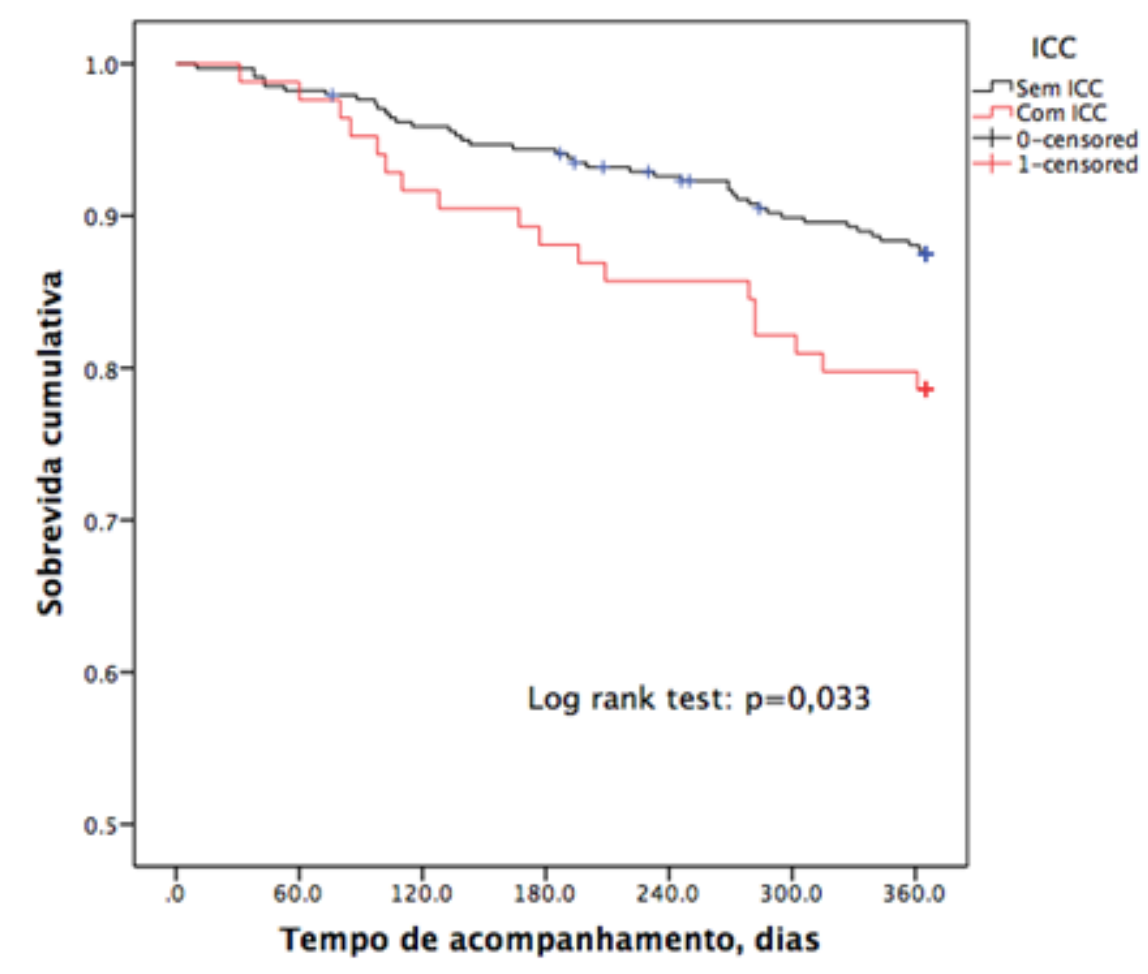

Figura 5. Curva de sobrevida de acordo com a presença de ICC

Os resultados mostraram que os pacientes sem ICC que sobreviveram eram mais jovens e com níveis de pressão arterial diastólica mais elevada. A presença de acesso vascular definitivo no final do primeiro ano permaneceu como um fator determinante na sobrevida, independente da presença de ICC (Tabela 7). 
Tabela 7. Características clínicas dos pacientes sobreviventes e não-sobreviventes de acordo com a presença ou não de ICC

\begin{tabular}{|c|c|c|c|c|c|c|}
\hline \multirow[b]{2}{*}{ Variável } & \multicolumn{3}{|c|}{ Grupo sem ICC } & \multicolumn{3}{|c|}{ Grupo com ICC } \\
\hline & $\begin{array}{l}\text { Sobreviventes } \\
\qquad N=298\end{array}$ & $\begin{array}{c}\text { Não } \\
\text { Sobreviventes } \\
N=42\end{array}$ & $\mathbf{p}$ & $\begin{array}{l}\text { Sobreviventes } \\
\qquad N=66\end{array}$ & $\begin{array}{c}\text { Não } \\
\text { Sobreviventes } \\
N=18\end{array}$ & $\mathbf{p}$ \\
\hline Idade (anos) & $47(32 ; 58)$ & $62(51 ; 72)$ & 0,0001 & $54(46 ; 67)$ & $60(50 ; 75)$ & 0,512 \\
\hline Raça (Branco) & $206(69)$ & $30(71)$ & 0,762 & $45(68)$ & $12(67)$ & 0,903 \\
\hline Sexo (Masculino) & $174(58)$ & $21 /(50)$ & 0,302 & $44(67)$ & $10(56)$ & 0,409 \\
\hline \multicolumn{7}{|l|}{ Etiologia DRC } \\
\hline Hipertensão arterial & $95(32)$ & $10(24)$ & & $22(33)$ & $8(44)$ & \\
\hline Diabetes mellitus & $70(23)$ & $14(33)$ & & $34(52)$ & $7(39)$ & \\
\hline Glomerulonefrite crônica & $48(16)$ & $3(7)$ & 0,278 & $1(2)$ & $1(6)$ & 0,65 \\
\hline Doença renal policística do adulto & $9(3)$ & $1(2)$ & & $2(3)$ & $0(0)$ & \\
\hline Outras & $76(26)$ & $14(33)$ & & $7(11)$ & $2(11)$ & \\
\hline \multicolumn{7}{|l|}{ Fatores de risco } \\
\hline Tabagismo & $60(20)$ & $12(29)$ & 0,21 & $9(14)$ & $2(11)$ & 0,778 \\
\hline Dislipidemia & $148(50)$ & $18(43)$ & 0,409 & $33(50)$ & $8(44)$ & 0,676 \\
\hline Insuficiência coronariana & $33(11)$ & $3(7)$ & 0,438 & $17(26)$ & $4(22)$ & 0,759 \\
\hline Insuficiência vascular periférica & $23(8)$ & $2(5)$ & 0,492 & $5(8)$ & $3(17)$ & 0,244 \\
\hline Hipertensão arterial & $284(95)$ & $39(93)$ & 0,496 & $65(98)$ & $18(100)$ & 0,599 \\
\hline Diabetes mellitus & $86(29)$ & $17(40)$ & 0,125 & $40(61)$ & 7 (39) & 0,100 \\
\hline \multicolumn{7}{|l|}{ 1ํAcesso Vascular } \\
\hline $\mathrm{CDL}$ & $260(87)$ & $40(95)$ & & $62(94)$ & $17(94)$ & \\
\hline FAV & $12(4)$ & $1(2)$ & 0,302 & $3(5)$ & $0(0)$ & 0,409 \\
\hline Catéter tunelizado & $26(9)$ & $1(2)$ & & $1(2)$ & $1(6)$ & \\
\hline PTFE & $0(0)$ & $0(0)$ & & $0(0)$ & $0(0)$ & \\
\hline \multicolumn{7}{|l|}{$\begin{array}{l}\text { Acesso vascular ao final do } \\
\text { seguimento }\end{array}$} \\
\hline CDL & $6(2)$ & $6(14)$ & & $2(3)$ & $4(22)$ & \\
\hline FAV & 235 (79) & $23(55)$ & 0,0001 & $54(82)$ & $6(33)$ & 0,001 \\
\hline Catéter tunelizado & $56(19)$ & $13(31)$ & & $9(14)$ & 7 (39) & \\
\hline PTFE & $1(0)$ & $0(0)$ & & $1(2)$ & $1(6)$ & \\
\hline \multicolumn{7}{|l|}{ PA pré-diálise } \\
\hline PA sistólica & $153,4 \pm 23,6$ & $150,6 \pm 23,8$ & 0,409 & $149,5 \pm 22$ & $147,6 \pm 27,6$ & 0,684 \\
\hline PA diastólica & $87,7 \pm 16$ & $82 \pm 16,7$ & 0,006 & $83,4 \pm 13$ & $79,9 \pm 14$ & 0,226 \\
\hline
\end{tabular}

Resultados expressos em mediana (min;máx), $\mathrm{n}(\%)$ ou média $\pm \mathrm{DP} ; \mathrm{CDL}$ : catéter duplo lúmen; FAV: fistula arteriovenosa; PTFE: enxerto arteriovenoso sintético; PA: pressão arterial 
Em relação aos resultados laboratoriais, pacientes sem ICC que não sobreviveram tinham níveis de uréia, creatinina, fósforo, colesterol total, triglicérides e ferro sérico significativamente mais baixos e níveis de PCR mais elevados que os sobreviventes. No grupo de pacientes com ICC, os resultados dos exames laboratoriais não foram diferentes entre os dois grupos (Tabela 8).

\section{Tabela 8. Características laboratoriais dos pacientes sobreviventes e não- sobreviventes com e sem insuficiência cardíaca congestiva}

\begin{tabular}{|c|c|c|c|c|c|c|}
\hline \multirow[b]{2}{*}{ Variável } & \multicolumn{3}{|c|}{ Grupo sem ICC } & \multicolumn{3}{|c|}{ Grupo com ICC } \\
\hline & $\begin{array}{l}\text { Sobreviventes } \\
\qquad N=298\end{array}$ & $\begin{array}{c}\text { Não } \\
\text { Sobreviventes } \\
\mathbf{N}=42\end{array}$ & $\mathbf{p}$ & $\begin{array}{c}\text { Sobreviventes } \\
\qquad N=66\end{array}$ & $\begin{array}{c}\text { Não } \\
\text { Sobreviventes } \\
N=18\end{array}$ & $\mathbf{p}$ \\
\hline Creatinina, mg/dL & $9,4(7,0 ; 14,6)$ & $7,7(6,2 ; 10)$ & 0,010 & $7,6(5,7 ; 11,6)$ & $8,0(5,9 ; 11,2)$ & 0,909 \\
\hline Ureia, mg/dL & $218(175 ; 280)$ & $183(152 ; 221)$ & 0,004 & $203(179 ; 248)$ & $212,5(174 ; 270)$ & 0,913 \\
\hline Hemoglobina, g/dL & $8,8(7,6 ; 10,3)$ & $8,6(7,6 ; 9,6)$ & 0,481 & $9,0(7,8 ; 10,3)$ & $8,4(7,6 ; 9,0)$ & 0,237 \\
\hline Hematócrito, \% & $27,2(23,5 ; 31,2)$ & $26,6(23,9 ; 30,1)$ & 0,842 & $28(24,4 ; 31,7)$ & $26,1(24,6 ; 27,5)$ & 0,185 \\
\hline Cálcio iônico, mg/dL & $4,5(4,1 ; 4,8)$ & $4,8(4,4 ; 5,0)$ & 0,013 & $4,6(4,3 ; 4,9)$ & $4,6(4,4 ; 4,9)$ & 0,650 \\
\hline Fósforo, mg/dL & $7,1(5,8 ; 8,7)$ & $5,9(4,9 ; 7,8)$ & 0,009 & $6,3(5,0 ; 8,0)$ & $5,8(5,1 ; 6,2)$ & 0,194 \\
\hline Fosfatase alcalina, U/L & $86(69 ; 124)$ & $97(74 ; 131)$ & 0,112 & $94(77 ; 128)$ & $109(96 ; 174)$ & 0,152 \\
\hline $\begin{array}{l}\text { 25(OH) vitamina } D \text {, } \\
\mathrm{ng} / \mathrm{mL}\end{array}$ & $12,8(8,0 ; 18,9)$ & $13(7 ; 15)$ & 0,373 & $11(7,0 ; 16,4)$ & $11,8(8,0 ; 14)$ & 0,851 \\
\hline Paratormônio, pg/mL & $182(48 ; 413)$ & $146(43 ; 315)$ & 0,299 & $152(62 ; 339)$ & $172,5(54 ; 383)$ & 0,736 \\
\hline FGF- 23, pg/mL & $2039(672,1 ; 4594)$ & $1371(365 ; 4446,7)$ & 0,354 & $1631(684 ; 3741,3)$ & 2267 (602 ; 2855) & 0,948 \\
\hline Triglicérides, mg/dL & $157(112 ; 229)$ & $127(91 ; 174,5)$ & 0,045 & $120(85 ; 179)$ & $131(77 ; 156)$ & 0,586 \\
\hline Colesterol total, $\mathrm{mg} / \mathrm{dL}$ & $178(147 ; 206)$ & $154(131 ; 204)$ & 0,076 & $169,5(13,5 ; 200)$ & $156(120 ; 217)$ & 0,521 \\
\hline LDL colesterol, mg/dL & $95,5(75 ; 120,5)$ & $89(56 ; 125)$ & 0,209 & $97(70 ; 113)$ & $94,5(70 ; 137)$ & 0,988 \\
\hline HDL colesterol, mg/dL & $43(35 ; 54)$ & $42(33 ; 59)$ & 0,978 & $43(34 ; 61)$ & $45(35 ; 55)$ & 0,811 \\
\hline Albumina, g/dL & $3,3(2,8 ; 3,8)$ & $3,2(2,7 ; 3,7)$ & 0,431 & $3,2(2,8 ; 3,6)$ & $3,2(3,0 ; 3,4)$ & 0,840 \\
\hline Proteína C Reativa, mg/L & $13,1(5,4 ; 41,1)$ & $30,5(8,6 ; 67,3)$ & 0,029 & $18,7(8,2 ; 47,4)$ & $40,9(9,8 ; 121)$ & 0,241 \\
\hline Glicose, mg/dL & $88(55 ; 291)$ & $91(66 ; 404)$ & 0,458 & $83(62 ; 482)$ & $87(77 ; 222)$ & 0,311 \\
\hline Ferro, $\mu \mathrm{g} / \mathrm{dL}$ & $54(40 ; 80)$ & $42(23 ; 59,5)$ & 0,006 & $49(35 ; 60)$ & $43(30 ; 71)$ & 0,995 \\
\hline Ferritina, $\mathrm{ng} / \mathrm{mL}$ & $373,6(207,4 ; 639,1)$ & $329,5(201,5 ; 589,3)$ & 0,437 & $281,9(130,2 ; 482,8)$ & $207,5(120 ; 326,2)$ & 0,303 \\
\hline ISAT, \% & $22,4(15,2 ; 31,3)$ & $18,1(12,5 ; 31)$ & 0,153 & $21(13,4 ; 30)$ & $22,9(13,9 ; 30,1)$ & 0,898 \\
\hline NT-pró-BNP , pg/mL & $4524(921,7 ; 11190)$ & $4565(1004 ; 14837)$ & 0,828 & $6224,5(2296 ; 23231)$ & $5577(1693 ; 27732)$ & 0,929 \\
\hline
\end{tabular}




\subsection{Análise de sobrevida dos pacientes de acordo com a presença ou não de ICC}

Ao término de 1 ano, 60 pacientes faleceram (14,1\%) e nove receberam um transplante renal (2,1\%). O tempo entre a admissão e o óbito variou de 10 a 363 dias (mediana de 188 dias).

\section{Pacientes sem ICC}

$\mathrm{Na}$ admissão, os pacientes sem ICC que sobreviveram usavam com mais frequência medicações do grupo IECA/BRA (38\% vs. 18\%, $p=0,003)$, hipoglicemiantes (26 vs. 13\%, $p=0,025$ ) e anti-agregantes plaquetários (38 vs. $24 \%, p=0,047$ ) que os que não sobreviveram.

Quando consideramos as medicações usadas pelos pacientes ao longo do 1 ano de diálise, detectamos novamente uso mais frequente entre os sobreviventes do que entre os não-sobreviventes de IECA/BRA (36 vs 20\%, $p=0,019$ ) e hipoglicemiantes ( $31 \%$ vs. $14 \%, p=0,007)$, assim como o uso de anti-agregantes (50\% vs. $45 \%, p=0,047)$.

Infecções do acesso vascular $(p=0,033)$, pulmonares $(p=0,049)$, hospitalizações por infecção do acesso vascular $(p=0,0001)$ e por doenças cardiovasculares $(p=0,001)$ também contribuíram para uma menor sobrevida desses pacientes.

A Figura 7 mostra a curva de sobrevida de acordo com o tipo de acesso vascular. A presença de FAV ao final do seguimento foi associada à maior sobrevida $(p=0,001)$. 


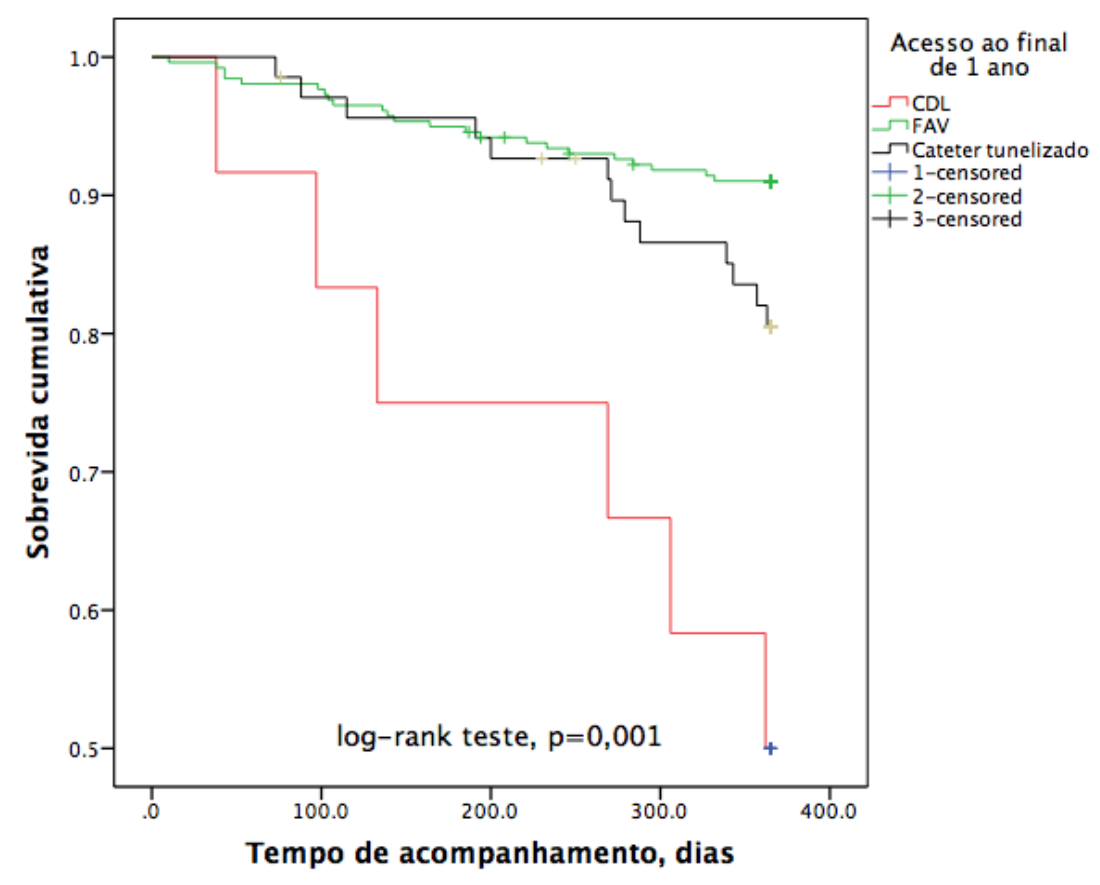

Figura 6. Curva de sobrevida em pacientes sem ICC de acordo com tipo de acesso vascular

\section{Pacientes com ICC}

Tanto na admissão como no seguimento não identificamos nenhuma medicação que se associou a maior sobrevida nesse grupo de pacientes.

Infecções tanto de acesso vascular como por outras causas, foram mais frequentes entre os não-sobreviventes ( 100 vs. $79 \%, p=0,032$ ), assim como as hospitalizações por infecções (61 vs. $35 \%, p=0,044$ ). Novamente a presença de FAV associou-se ao aumento de sobrevida dos pacientes, mesmo com ICC, ao final do $1^{\circ}$ ano $(p=0,001)$, conforme demonstrado na Figura 8. 


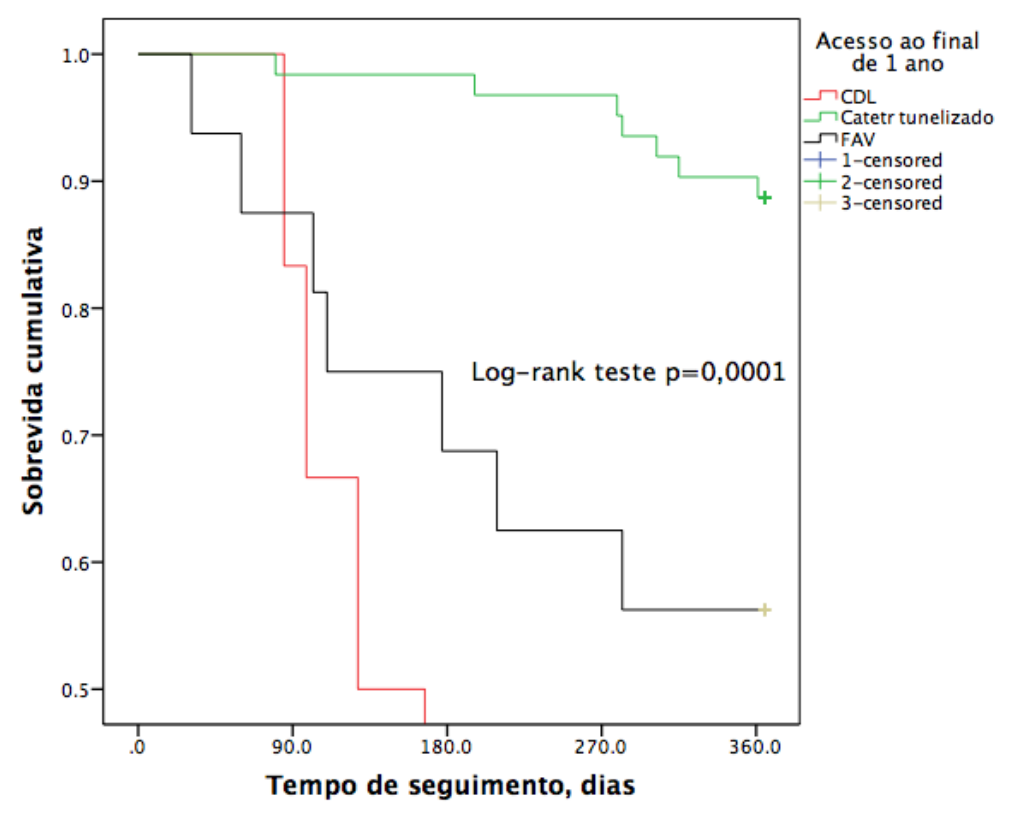

Figura 7. Curva de sobrevida em pacientes com ICC de acordo com tipo de acesso vascular

\subsection{Fatores prognósticos de mortalidade}

Para identificar os fatores associados à mortalidade, realizamos a análise de regressão de Cox. Incluímos no modelo todas as variáveis que na análise univariada obtiveram significância, definida como $p<0,05$.

Como os fatores que levam à mortalidade estão intimamente relacionados e, portanto, são colineares, propusemos modelos no sentido de agrupar variáveis como idade, DM, ICC, acesso vascular, resultados dos exames laboratoriais e medicações usadas, bem como o tipo de acesso vascular, incluindo todos os pacientes (Tabela 9), os pacientes sem ICC (Tabela 10) e os pacientes com ICC (Tabela 11). 
Tabela 9. Fatores de risco e mortalidade incluindo todos os pacientes

\begin{tabular}{|c|c|c|c|c|c|}
\hline Fatores de risco & $\beta$ & HR & \multicolumn{2}{|c|}{ IC 95\% } & p \\
\hline \multicolumn{6}{|l|}{ Modelo 1} \\
\hline Idade & 0,034 & 1,034 & 1,018 & 1,051 & $<0,001^{*}$ \\
\hline DM & $-0,113$ & 0,893 & 0,529 & 1,508 & 0,673 \\
\hline ICC & 0,289 & 1,335 & 0,746 & 2,389 & 0,330 \\
\hline \multicolumn{6}{|l|}{ Acesso vascular, CDL } \\
\hline FAV vs. CDL & $-1,965$ & 0,140 & 0,068 & 0,290 & $<0,001^{*}$ \\
\hline Tunelizado vs. CDL & $-0,888$ & 0,411 & 0,189 & 0,897 & $0,026^{*}$ \\
\hline \multicolumn{6}{|c|}{ Modelo 1 + uréia/triglicérides/sevelamer } \\
\hline Uréia & $-0,030$ & 0,997 & 0,993 & 1,000 & 0,060 \\
\hline Triglicérides & $-0,004$ & 0,996 & 0,992 & 1,000 & $0,034^{*}$ \\
\hline Sevelamer & $-0,643$ & 0,562 & 0,312 & 0,886 & $0,016^{*}$ \\
\hline
\end{tabular}

Ao analisarmos as variáveis escolhidas incluindo todos os pacientes detectamos um aumento significativo do risco de mortalidade nos pacientes mais idosos, enquanto naqueles com FAV e catéter tunelizado, o risco foi menor comparando com os pacientes com CDL. Quanto às outras variáveis analisadas, níveis menores de uréia e triglicérides e o uso de sevelamer contribuíram para aumentar a mortalidade dos pacientes. 
Tabela 10. Fatores de risco e mortalidade incluindo os pacientes sem insuficiência cardíaca congestiva

\begin{tabular}{|c|c|c|c|c|c|}
\hline Fatores de risco & $\beta$ & HR & \multicolumn{2}{|c|}{ IC 95\% } & $\mathbf{p}$ \\
\hline \multicolumn{6}{|l|}{ Modelo 1} \\
\hline Idade & 0,041 & 0,000 & 1,042 & 1,022 & 1,063 \\
\hline \multicolumn{6}{|l|}{ Acesso vascular, CDL } \\
\hline FAV vs. CDL & $-2,001$ & 0,000 & 0,135 & 0,055 & 0,335 \\
\hline Tunelizado vs. CDL & $-1,204$ & 0,015 & 0,300 & 0,113 & 0,795 \\
\hline \multicolumn{6}{|c|}{ Modelo 1 + uréia/colesterol/triglicérides } \\
\hline Uréia & $-0,005$ & 0,995 & 0,991 & 0,999 & $0,024^{*}$ \\
\hline Colesterol & $-0,007$ & 0,993 & 0,986 & 1,001 & 0,096 \\
\hline Triglicérides & $-0,004$ & 0,996 & 0,991 & 1,000 & 0,070 \\
\hline
\end{tabular}

Nos pacientes sem ICC, não observamos nenhum aumento no risco de morte dependente de idade e acesso vascular, enquanto níveis mais baixos de ureia contribuem para aumento da mortalidade, provavelmente refletindo estado nutricional inadequado.

Tabela 11. Fatores de risco e mortalidade incluindo os pacientes com insuficiência cardíaca congestiva

\begin{tabular}{|c|c|c|c|c|c|}
\hline Fatores de risco & $\beta$ & HR & \multicolumn{2}{|c|}{ IC 95\% } & p \\
\hline \multicolumn{6}{|l|}{ Modelo 1} \\
\hline $\mathrm{DM}$ & $-0,825$ & 0,100 & 0,438 & 0,164 & 1,173 \\
\hline \multicolumn{6}{|l|}{ Acesso vascular, CDL } \\
\hline FAV vs. CDL & $-2,186$ & 0,001 & 0,112 & 0,032 & 0,400 \\
\hline Tunelizado vs. CDL & $-0,435$ & 0,507 & 0,647 & 0,179 & 2,343 \\
\hline Modelo 1 + sevelamer & $-1,409$ & 0,244 & 0,088 & 0,678 & $0,007^{*}$ \\
\hline
\end{tabular}

No grupo de pacientes com ICC, somente o uso de sevelamer foi um fator de proteção para a mortalidade. 


\section{DISCUSSÃO}

Neste estudo, analisamos 424 pacientes incidentes em hemodiálise atendidos inicialmente em serviço de emergência sendo que, a grande maioria, não fazia acompanhamento com nefrologistas. Como somente 16 deles tinham FAV, inferimos que esses, eram acompanhados por especialista, ou seja, 3,8\% dos pacientes estudados. Sabidamente pacientes incidentes em hemodiálise apresentam altas taxas de mortalidade. Em nosso meio, estudo recente de Jimenes e cols., mostrou uma taxa de $25 \%$, ou seja, muito superior à que observamos que foi de $14 \%$. A comparação dos dois estudos mostrou que a porcentagem de diabéticos e de fumantes era maior no estudo de Jimenes o que poderia explicar a diferença encontrada. ${ }^{79}$

Vale ressaltar que, no presente estudo as condições clinicas dos pacientes na admissão eram preocupantes, pois a maioria estava hipertensa, sem acesso vascular, anêmicos, com alteração do metabolismo mineral, muitos sem tratamento especifico para DM, HA e dislipidemia, com níveis de PCR elevados e sinais indiretos de desnutrição revelando falha no atendimento básico de saúde. Mesmo com condições iniciais tão adversas a mortalidade foi baixa em relação a outros estudos, o que pode ser atribuída a qualidade da dialise ofertada no seguimento, e também ao fato de a maioria dos pacientes retornarem a um hospital de alta complexidade para tratamento das intercorrências clínicas.

Recentemente uma revisão realizada pela Cochrane Database of Systematic Reviews analisou os resultados de 40 estudos com um total de 63.887 pacientes dos quais 43.209 foram encaminhados precocemente para seguimento com nefrologistas e 20.678 mais tardiamente. Os resultados mostraram redução da mortalidade, da taxa de hospitalização, e maior número de pacientes com via de acesso para hemodiálise, naqueles encaminhados precocemente para o especialista. ${ }^{80}$

A maioria dos pacientes, aqui estudados, não tinha acesso vascular para hemodiálise o que impactou muito na sobrevida dos mesmos, a tal ponto que 
aqueles com ICC, comorbidade que mais levou ao óbito, tiveram maior sobrevida quando tinham FAV .

Registros internacionais sugerem que pelo menos $50 \%$ dos pacientes inicie o tratamento dialítico usando FAV, muito distante do que detectamos no nosso estudo. $81,82,83,84,85,86,87$

Malas e cols. realizaram um estudo retrospectivo usando dados do registro americano (USRDS) no qual estudaram 510.000 pacientes. A maioria $(82,6 \%)$ iniciou HD com CDL e somente $14 \%$ com FAV e o impacto foi uma menor mortalidade nos pacientes com FAV (23\%). Esses resultados são semelhantes aos nossos. Vários fatores foram abordados pelos autores justificando o porquê da falta de FAV em pacientes de um país com mais recurso que o nosso. Dentre eles o acompanhamento tardio pelos nefrologistas a demora no encaminhamento para o cirurgião vascular, além de problemas anatômicos que dificultam a realização da fistula. A proposta seria a criação de equipes multidisciplinares para o acompanhamento desses pacientes o que, em principio, também poderia ser adotado no nosso meio. ${ }^{88}$

Ao final de um ano $75 \%$ dos nossos pacientes tinham FAV e quando analisamos os fatores que impactam na sobrevida, novamente detectamos que tanto a FAV como o catéter tunelizado protegeram a vida dos pacientes mais do que quando dialisavam com CDL.

As infecções relacionadas aos acessos vasculares são a fonte identificável, mais comum de infecção nos pacientes em HD contribuindo para aumentar a mortalidade dos mesmos, o que também foi observado no nosso estudo. ${ }^{89}$ Além de aumentar a mortalidade, o custo direto e indireto com hospitalizações é elevado podendo atingir cifras consideráveis. No nosso meio esses valores são desconhecidos, mas dados de literatura revelaram que variam de 17.000 a 32.000 dólares por paciente. ${ }^{90}$

Cerca de $80 \%$ dos pacientes estudados apresentavam níveis de hemoglobina menores que 11g. Não detectamos impacto da anemia na mortalidade, no entanto ela é considerada um fator de risco não tradicional no desenvolvimento de DCV, pois contribui para a hipertrofia miocárdica e indiretamente para maior mortalidade dos pacientes com DRC. ${ }^{91}$ Também não 
detectamos impacto dos distúrbios lipídicos, fatores de risco que aumentam a mortalidade tanto de indivíduos normais como de pacientes com DRC.O perfil lipídico dos pacientes sugeria mais desnutrição, pois cerca de $50 \%$ deles tinham níveis de colesterol inferiores a $200 \mathrm{mg} / \mathrm{dl}$. Os pacientes que não sobreviveram apresentavam alem de, níveis menores de colesterol, redução dos níveis de triglicérides, de ureia, creatinina, fósforo e de ferro sérico assim como níveis elevados de PCR. No entanto não dispúnhamos de dados como peso corpóreo, altura, índice de massa corpórea, assim como de informações sobre perda de peso recente, recordatório alimentar, sintomas gastrointestinais e capacidade funcional dos pacientes para confirmar a presença ou não de desnutrição. A desnutrição proteico-calórica associada à inflamação tem sido muito estudada, nos últimos anos, como um fator de risco que aumenta a mortalidade dos pacientes com DRC. ${ }^{92,93}$

Quanto aos distúrbios do metabolismo mineral, presente na maioria dos pacientes, os níveis de cálcio e fosfatase alcalina eram mais elevados nos que não sobreviveram o que poderia refletir aumento da remodelação óssea enquanto os níveis reduzidos de fósforo associado a outras alterações laboratoriais já descritas apontam para desnutrição.

Somente os níveis séricos de $25(\mathrm{OH})$ vitamina D muito reduzidos (menores que $15 \mathrm{ng} / \mathrm{ml}$ ) aumentaram em duas vezes, o risco de morte dos pacientes. A deficiência de vitamina $D$ é muito prevalente em pacientes com DRC e se associa com vários desfechos clínicos, como por ex dobrar os níveis séricos de creatinina em pacientes com doença renal, de modo independente de outros fatores de risco. Associa-se também, com piora da anemia, fraqueza muscular, calcificação vascular, disfunção endotelial e eventos cardiovasculares. Os níveis séricos de $25(\mathrm{OH})$ vitamina $D$ são influenciados por vários fatores como por ex sazonalidade, atividade física,presença ou não de inflação, DM e proteinúria, que não puderam ser analisados nesse estudo. Recentemente nosso grupo avaliou os níveis de $25(\mathrm{OH})$ vitamina $D$ em indivíduos normais ${ }^{94}$, no inverno e no verão e os valores encontrados 22,0 $\mathrm{ng} / \mathrm{ml}$ e $34,0 \mathrm{ng} / \mathrm{ml}$, respectivamente, eram superiores aos que observamos nos paciente estudados que foi de $12,3 \mathrm{ng} / \mathrm{ml}$. Nossos resultados são contundentes 
quanto à deficiência dessa vitamina aumentar o risco de morte dos pacientes e vai de encontro a outros, já publicados, o que reforça a necessidade de sua reposição e controle nos pacientes com DRC. ${ }^{95,96,97}$

Nos últimos anos várias publicações demonstraram que os níveis séricos de FGF-23, se associam com aumento da mortalidade, progressão da doença renal e desenvolvimento de DCV. ${ }^{98,99,100}$ Sabe-se que esse hormônio promove hipertrofia dos cardiomiócitos. Nossos resultados não demonstraram diferenças na concentração de FGF-23 entre os pacientes sobreviventes e não sobreviventes, inclusive naqueles com ICC. Os níveis séricos de FGF-23 eram muito elevados em praticamente todos os pacientes, dificultando detectar diferenças e assim compreender seu papel na sobrevida e nas complicações apresentadas pelos mesmos.

Os níveis de NT-pró-BNP também estavam muito elevados nos pacientes estudados, no entanto permitiu diferenciar aqueles com ICC, visto que é usado com essa finalidade. No entanto não se associou com mortalidade. ${ }^{101,102}$

Quanto às medicações usadas pelos pacientes durante o seguimento, os resultados mostraram que os hipotensores do grupo IECA-BRA e antiagregantes plaquetários foram mais usados nos pacientes não sobreviventes, 0 que provavelmente ocorreu pela maior gravidade do quadro clinico. Ao analisarmos aqueles com ICC notamos o inverso, ou seja, os que usavam essas medicações e também hipoglicemiantes tanto na admissão como no seguimento sobreviveram mais que os que não usavam mostrando serem protetores mesmo diante de uma complicação grave como a ICC.

Os efeitos protetores do quelante de fósforo cloridrato de sevelamer na sobrevida de pacientes com DRC, já foram descritos e também observados nos nossos resultados. ${ }^{101}$ Esse quelante além de reduzir os níveis séricos de fósforo, por si só deletérios, diminui os níveis de colesterol, FGF-23, e dos AGEs (produtos avançados da glicosilação), além de diminuir a sobrecarga de cálcio produzida pelos quelantes a base de cálcio. ${ }^{101,102,103}$ Ao identificar os fatores associados a mortalidade o uso de sevelamer foi um fator protetor importante para todos os pacientes e particularmente naqueles com ICC sugerindo que esse grupo se beneficiaria do seu uso. ${ }^{104,105}$ 
Nesse estudo a expectativa de vida dos pacientes com ICC foi menor dos que os que não tinham essa complicação.

Na população americana, a ICC é a principal causa de hospitalização de pacientes acima dos 65 anos atingindo anualmente cerca de um milhão de indivíduos com uma mortalidade de 300.000 pacientes/ano. A associação entre DRC e DCV esta bem estabelecida, os dois sistemas se comunicam e processos patológicos se desencadeiam acelerando a disfunção de ambos. Esse processo é conhecido como síndrome cardiorrenal. ${ }^{106,107,108}$

Nossos resultados confirmaram o que já esta estabelecido na literatura ou seja as DCV foram as principais causas de óbito dos pacientes aqui estudados. ${ }^{109}$ Dentre elas a ICC influenciou a expectativa de vida de forma significativa. Vale ressaltar que, a não ser pela dosagem de Nt-pró-BNP, o diagnóstico de ICC foi predominantemente clinico. Dentre os pacientes com ICC não encontramos diferenças clínicas e laboratoriais entre os sobreviventes e não sobreviventes.

Ao identificar os fatores associados à mortalidade a idade só não esteve presente nos pacientes com ICC, ou seja, a presença dessa complicação é grave em qualquer idade. Novamente a via de acesso para hemodiálise, especialmente FAV, protege os pacientes.

Mesmo sem analisar adequadamente o estado nutricional dos pacientes podemos inferir que a desnutrição favorece a mortalidade, evidenciado pelos níveis mais elevados de uréia e triglicérides que protegeram os pacientes como um todo e os níveis menores de uréia e colesterol que se associam a maior mortalidade dos pacientes com ICC. 


\section{CONCLUSÕES}

1: Neste estudo a mortalidade de pacientes incidentes em hemodiálise foi semelhante a descrita na literatura.

2: As condições clinicas dos pacientes ao serem admitidos no serviço de emergência eram bastante adversas mas provavelmente a qualidade da diálise ofertada e o tratamento das intercorrências clínicas durante o seguimento contribuíram para que a mortalidade fosse semelhante a descrita na literatura.

3: A falta de via de acesso impactou na sobrevida dos pacientes.

4: As doenças cardiovasculares foram as principais causas de óbitos nesse grupo de pacientes.

5: Dentre os distúrbios do metabolismo mineral a deficiência de $25(\mathrm{OH})$ vitamina $D$ impactou na sobrevida dos pacientes. 


\section{REFERÊNCIAS}

1. Bauer C, Melamed ML, Hostetter TH: Staging of chronic kidney disease: time for a course correction. J Am Soc Nephrol. 2008, May:19(5): 844-6.

2. Stevens PE, Levin A : Evaluation and management of chronic kidney disease: synopsis of the kidney disease: improving global outcomes 2012 clinical practice guideline. Ann Intern Med (2013), 158 (11): 825-30.

3. Oliveira MB, Romão JE Jr, Zatz R: End-stage renal disease in Brazil: epidemiology, prevention, and treatment. Kidney Int. 2005; 97: S 82- 6.

4. Lugon, JR: End-stage renal disease and chronic kidney disease in Brazil. Ethn Dis. 2009,Spring;19 (1 Suppl 1):S 1-7-9.

5. Sesso RC, Lopes AA, Thomé FS, Lugon JR, Dos Santos DR: Brazilian Chronic Dialysis Survey 2013 - trend analysis between 2011 and 2013. J Bras Nefrol.2014, Oct -Dec: 36(4): 476-81.

6. GBD 2013 Mortality and Causes of Death Collaborators: Global, regional, and national age sex specific all cause and cause - specific mortaliy for 240 causes of death, 1990 - 2013: a Systematic analysis for the Global Burden of Disease Study 2013. Lancet. 2015; Jan 10;385 (9963): 117 - 71.

7. United States Renal Data System (USRDS) 2014 - www.usrds.org. Acesso: 23/07/2015.

8. Kidney Disease: Improving Global Outcomes (KDIGO) CKD Work Group: KDIGO 2012 clinical practice guideline for the evaluation and management of chronic kidney disease. Kidney Int Suppl 2013;3(1):1-150. 
9. Ishani A, Gilbertson D.T, Kim D, Bradbury B.D, Collins A.J: Predialysis Care and Dialysis Outcomes in Hemodialysis Patients with a Functioning Fistula. Am J Nephrol. 2014; 39(3):238-47.

10. Sclieper G, Hess K, Floege J, Marx N: The vulnerable patient with chronic kidney disease. Nephrol Dial Transplant 2015; Mar 4. pii: gfv041.

11. Robinson BM, Zhang J, Morgenstern $\mathrm{H}$ et al: Worldwide, mortality risk is high soon after initiation of hemodialysis. Kidney Int. 2014; 85: 158 - 165.

12. BUCHARLES, Sérgio Gardano Elias; VARELA, Alexandre $M$; BARBERATO, Silvio Henrique and PECOITS-FILHO, Roberto: Avaliação e manejo da doença cardiovascular em pacientes com doença renal crônica. J. Bras. Nefrol. 2010, vol.32, n.1, pp. 120-127.

13. de Jager DJ, Grootendorst DC, Jager KJ, van Dijk PC, Tomas LM, Ansell D, Collart F, Finne P, Heaf JG, De Meester J, Wetzels JF, Rosendaal FR, Dekker FW: Cardiovascular and noncardiovascular mortality among patients starting dialysis. JAMA 2009; 302: 1782-1789.

14. Longenecker JC, Coresh J, Powe NR, Levey AS, Fink NE, Martin A, Klag MJ: Traditional cardiovascular disease risk factors in dialysis patients compared with the general population: The CHOICE Study. J Am Soc Nephrol 2002;13: 1918-1927.

15. Pun, PH: The interplay between CKD, sudden cardiac death, and ventricular arrhythmia. Adv Chronic Kidney Dis, 2014;Nov;21(6): 480-8.

16. Floege J, Gillespie IA, Kronenberg F, Anker SD, Gioni I, Richards S, Pisoni RL, Robinson BM, Marcelli D, Froissart M, Eckardt KU: Development and validation of a predictive mortality risk score from a European hemodialysis cohort. Kidney Int. 2015 May; 87(5): 996-1008. 
17. Sozio SM,Armstrong PA,Coresh J,Jaar BG, Fink NE, Plantinga LC, Powe NR,Parekh RS: Cerebrovascular disease incidence characteristics, and outcomes in patients iniating dialysis: the choices for healthy outcomes in caring for ESRD (CHOICE) study. Am J Kidney Dis. 2009;Sep;54(3): 468-77.

18. Herzog CA, Asinger RW, Berger AK, Charytan DM, Díez J, Hart RG, Eckardt KU, Kasiske BL, McCullough PA, Passman RS, DeLoach SS, Pun PH, Ritz E: Cardiovascular disease in chronic kidney disease. A clinical update from Kidney Disease: Improving Global Outcomes (KDIGO). Kidney Int. 2011;Sep;80 (6): 572-86.

19. Pun PH, Lehrich RW, Honeycutt EF, Herzog CA, Middleton JP: , Modifiable risk factors associated with sudden cardiac arrest within hemodialysi s clinics. Kidney Int. 2011; Jan;79(2):218-27.

20. de Jager DJ, Grootendorst DC, Jager KJ, van Dijk PC, Tomas LM, Ansell D, Collart F, Finne P, Heaf JG, De Meester J, Wetzels JF, Rosendaal FR, Dekker FW: Cardiovascular and noncardiovascular mortality among patients starting dialysis. Jama 2009;Oct 28;302(16): 1782-9

21 Shivendra Singh: Cardiovascular disease in chronic kidney disease. Clinical Queries: Nephrology ,Volume 3, Issue 1, January- March 2014; Pages $20-29$.

21. Carrero JJ, Stenvinkel P: Inflammation in end-stage renal disease--what have we learned in 10 years?. Semin Dial. 2010; Sep-Oct;23(5):498-509.

22. Honda H, Qureshi AR, Heimbürger O, et al. Serum Albumin, C-Reactive Protein, Interleukin 6, and Fetuin A as Predictors of Malnutrition, Cardiovascular Disease, and Mortality in Patients With ESRD. Am J kidney Dis 2006; 47:139148. 
23. Pello AM, Cristóbal C, Tarín N, Huelmos A, Aceña Á, Carda R, Gonzalez Casaus ML,Alonso J, Lorenzo Ó, Blanco Colio L, Martín Ventura JL, Franco Peláez JÁ, Mahíllo Fernández I, Farré J, López-Bescós L,Egdo J, Tuñon J: Differential profile in inflammatory and mineral metabolismo biomarkers in patients with ischemic heart disease without classical coronary risk factors. J Cardiol. 2015; Jul;66(1): 22-7.

24. Owen WF, Lowrie EG: C-reactive protein as an outcome predictor for maintenance hemodialysis patients. Kidney Int. 1998, Aug ; 54 (2):627-636.

25. Chertow GM, Goldstein-Fuchs DJ, Lazarus JM, Kaysen GA : Prealbumin, mortality, and cause-specific hospitalization in hemodialysis patients. Kidney Int. 2005, Dec; 68 (6): 2794-2800.

26. Liu Y, Coresh J, Eustace JA, Longenecker JC, Jaar B, Fink NE, Tracy RP, Powe NR, Klag MJ: Association Between Cholesterol Level and Mortality in Dialysis Patients: Role of Inflammation and Malnutrition. JAMA 2004 ,Jan 28; 291 (4): 451-9.

27. Foley RN, Chen SC, Solid CA, Gilbertson DT, Collins AJ : Early mortality in patients starting dialysis appears to go unregistered. Kidney Int 2014, Aug; 86 (2): 392-8.

28. Block GA, Hulbert Shearon TE, Levin NW, Port FK: Association of serum phosphorus and calcium $x$ phosphate product with mortalit y risk in chronic hemodialysis patients: a national study. Am J Kidney Dis. 1998; Apr; 31 (4) : 607- 17.

29. Block GA, Klassen PS, Lazarus JM, Ofsthun N, Lowrie EG, Chertow GM: Mineral Metabolism, Mortality, and Morbidity in Maintenance Hemodialysis. $J$ Am Soc Nephrol 2004; Aug; 15 (8): 2208-18. 
30. Fernández-Martín JL, Martínez-Camblor $\quad \mathrm{P}$, Dionisi $\quad \mathrm{MP}$, Floege J, Ketteler M, London G, Locatelli F, Gorriz JL, Rutkowski B, Ferreira A, Bos WJ,Covic A, Rodríguez-García M, Sánchez JE, Rodríguez-Puyol D, CannataAndia JB; COSMOS group: Improvement of mineral and bone metabolism markers is associated with better survival in haemodialysis patients: the COSMOS study. Nephrol Dial Transplant. 2015 Sep; 30 (9):1542-51.

31. Miura S, Yoshihisa A, Takiguchi M, Shimizu T, Nakamura Y, Yamauchi H, Iwaya S, Owada T, Miyata M, Abe S, Sato T, Suzuki S, Oikawa M,Yamaki T, Sugimoto K, Kunii H, Nakazato K, Suzuki H, Saitoh S, Takeishi $Y$ : Association of Hypocalcemia With Mortality in Hospitalized Patients With Heart Failure and Chronic Kidney Disease. J Card Fail. 2015 Aug;21(8):621-27.

32. Naves-Diaz M, Passlick-Deetin J, Guinsburg A, Marelli C, FernándezMartín JL, Rodriguez Puyol D, Cannata-Andia JB: Calcium, phosphorus, PTH and death rates in a large sample of dialysis patients from Latim America. The CORES Study. Nephrol Dial Transplant. 2011;Jun;26(6): 1938-47

33. Giachelli CM, Jono S, Shioi A, Nishizawa $\mathrm{Y}$, Mori K, Morii H: Vascular calcification and inorganic phosphate. Am J Kidney Dis 2001; 38 [Suppl 1]: S 34-S37.

34. Wu M, Rementer C, Giachelli CM: Vascular calcification: an update on mechanisms and challenges in treatment. Calcif Tissue Int.2013; Oct;93(4):365-73.

35. Canziani ME, Moysés RM: Calcificação vascular na DRC. J Bras Nefrol. 2008; 30 (2): 23 - 6.

36. Barreto DV, Barreto Fde C, de Carvalho AB, Cuppari L, Draibe SA, Dalboni MA, Moyses RM, Neves KR, Jorgetti V, Miname M, Santos RD, Canziani ME: Phosphate binder impact on bone remodeling and coronary 
calcification-results from the BRiC study. Nephron Clin Pract. 2008; 110(4):273 -83 .

37. Barreto DV, Barreto Fde C, Carvalho AB, Cuppari L, Draibe SA, Dalboni MA, Moyses RM, Neves KR, Jorgetti V, Miname M, Santos RD, Canziani ME: Association of changes in bone remodeling and coronary calcification in hemodialysis patients: a prospective study. Am J Kidney Dis 2008;Dec;52(6): 1139-50.

38. Russo D, Miranda I, Ruocco C, Battaglia Y, Buonanno E, Manzi S, Russo L, Scarfato A, Andreucci VE: The progression of coronary artery calcification in predialysis patiensts on calcium carbonate or sevelamer . Kidney Int. 2007;Nov;72(10): 1255-6.

39. Shanahan CM, Crouthamel MH, Kapustin A, Giachelli CM,Arterial calcification in chronic kidney disease: Key roles for calcium and phosphate. Cir Res. 2001;Sep 2;109 (6): 697-711

40. Shantouf RS, Budoff MJ, Ahmadi N, Ghaffari A, Flores F, Gopal A, Noori N, Jing J, Kovesdy CP, Kalantar-Zadeh K, Shantouf RS, Budoff MJ, Ahma: Total and individual coronary artery calcium scores as independent predictors of mortality in hemodialysis patients. Am J Nephrol. 2010;31(5):419-25.

41. Ganesh SK, Stack AG, Levin NW, Hulbert-Shearon T, Port FK: Association of elevated serum $\mathrm{PO}(4), \mathrm{Ca} \times \mathrm{PO}(4)$ product, and parathyroid hormone with cardiac mortality risk in chronic hemodialysis patients. J Am Soc Nephrol. 2001 Oct ;12 (10): 2131 - 8.

42. Tentori F, Blayney MJ, Albert JM, Gillespie BW, Kerr PG, Bommer J, Young EW, Akizawa T, Akiba T, Pisoni RL, Robinson BM, Port FK: Mortality risk for dialysis patients with different levels of serum calcium, phosph orus, and PTH: the Dialysis Outcomes and Practice Patterns Study (DOPPS). Am J Kidney Dis. 2008 Sep;52(3):519-30. 
43. Tangri N, Wagner M, Griffith JL, Miskulin DC, Hodsman A, Ansell D, Naimark DM: Effect of Bone Mineral Guideline Target Achievement on Mortality in Incident Dialysis Patients: An Analysis of the United Kingdom Renal Registry, Am J Kidney Dis. 2011 Mar;57(3):415-21

44. Jung $\mathrm{HH}$, Kim SW, Han $\mathrm{H}$ : Inflammation, mineral metabolism and progressive coronary artery calcification in patients on haemodialysis. Nephrol Dial Transplant. 2006;Jul;21(7):1915-20.

45. Hajhosseiny, R., Khavandi, K. and Goldsmith, D. J. (2013), Cardiovascular disease in chronic kidney disease: untying the Gordian knot. International Journal of Clinical Practice, 67: 14-31.

46. Drechsler C, Evenepoel P, Vervloet MG, Wanner C, Ketteler M, Marx N, Floege J, Dekker FW, Brandenburg VM; NECOSAD Study Group, High levels of circulating sclerostin are associated with better cardiovascular survival in incident dialysis patients: results from the NECOSAD study. Nephrol Dial Transplant. 2015 Feb;30(2):288-93.

47. Ellam TJ, Chico TJ,Phosphate: the new cholesterol: The role of the phosphate axis in non uremic vascular disease. Atherosclerosis. 2012 Feb;220(2):310-8.

48. Cancela AL, Santos RD, Titan SM, Goldenstein PT, Rochitte CE, Lemos PA, dos Reis LM, Graciolli FG, Jorgetti V, Moysés RM: Phosphorus Is Associated with Coronary Artery Disease in Patients with Preserved Renal Function. PLoS One. 2012;7(5):e36883. doi: 10.1371/journal.pone.0036883

49. Tonelli M, Sacks F, Pfeffer M, Gao Z, Curhan G: Cholesterol And Recurrent Events Trial Investigators, Relation Between Serum Phosphate Level and Cardiovascular Event Rate in People With Coronary Disease. Circulation. 2005 Oct 25;112(17):2627-33. 
50. Neves, C.L.; Custódio, M.R.; Neves, K.R.; Moysés, R.M.; Jorgetti, V. O hiperparatireoidismo Secundário e a Doença Cardiovascular na Doença Renal Crônica. J. Bras. Nefrol 2008;30 (Supl.1):18 - 22.

51. Mejía N, Roman-García P, Miar AB, Tavira B, Cannata-Andía JB: Chronic kidney disease mineral and bone disorder: a complex scenario. Nefrologia. 2011; 31 (5): 514 - 19.

52. Neves KR, Graciolli FG, dos Reis LM, Graciolli RG, Neves CL, Magalhães AO, Custódio MR, Batista DG, Jorgetti V, Moysés RM: Vascular calcification: contribution of parathyroid hormone in renal failure. Kidney Int. 2007 Jun;71(12):1262-70.

53. Bellorin-Font E, Ambrosoni P, Carlini RG, Carvalho AB, Correa-Rotter R, Cueto-Manzano A, Jara A, Jorgetti V, Negri AL, Olaizola I, Salusky I, Slatopolsky E,Weisinger JR; Comité de Metabolismo Mineral y Óseo; Sociedad Latinoamericana de Nefrología e Hipertensión (SLANH), Clinicalpractice guidelines for the prevention, diagnosis, evaluation and treatment of mineral and bone disordersin chronic kidney disease (CKD-MBD) in adults. Nefrologia. 2013;33 Suppl 1:1-28.

54. Custodio MR, Koike MK, Neves KR,dos Reis LM, Graciolli FG, Neves CL, Batista DG, Magalhaes AO, Hawlitschek P,Olibeira IB, Dominguez WV, Moysés RM, Jorgetti $\mathrm{V}$ : Parathyroid hormone and phosphorus overload in uremia: impacto $\mathrm{n}$ cardiovascular system. Nephrol Dial Transplant 2012;Apr;27(4): 1437-45

55. Holick MF: Vitamin D deficiency. N Engl J Med 2007;357:266-81.

56. DINIZ, Herculano Ferreira; ROMAO, Mariana Fadil; ELIAS, Rosilene Motta and ROMAO JUNIOR, João Egídio: Insuficiência e deficiência de vitamina D em pacientes portadores de doença renal crônica. J. Bras. Nefrol. 2012, vol.34, n.1, p. 58-63. 
57. Wolf M,Shah A, Gutierrez O, Ankers E, Monroy M, Tamez H,Steele D, Chang Y, Camargo CA Jr, Tonelli M, Thadhani R: Vitamin D levels and early mortality among incidente hemodialysis patients. Kidney Int. 2007;Oct 72(8): 1004-13.

58. Cuppari L, Carvalho AB, Draibe SA: Vitamin D status of chronic kidney disease in patients living in a sunny country. $J$ Ren Nutr 2008;18:408-14.

59. Nagpal S, Na S, Rathnachalam R: Noncalcemic Actions of Vitamin D Receptor Ligands. Endocr Rev. 2005 Aug; 26(5):662-87.

60. Giovannucci E, Liu Y, Hollis BW, Rimm EB: 25-hydroxyvitamin D and risk of myocardial infarction in men: a prospective study. Arch Intern Med. 2008, Jun 9;168(11):1174-80.

61. Melamed ML, Michos ED, Post W, Astor B: 25-hydroxyvitamin $D$ levels and the risk of mortality in the general population. Arch Intern Med. 2008,Aug 11;168(15):1629-37.

62. Pilz S, Tomaschitz A, Friedl C, Amrein K, Drechsler C, Ritz E, Boehm BO, Grammer TB, März W: Vitamin D status and mortality in chronic kidney disease. Nephrol Dial Transplant. 2011, Nov;26(11):3603-9.

63. Berndt TJ, Schiavi S, Kumar R: "Phosphatonins" and the regulation of phosphorus homeostasis. Am J Physiol Renal Physiol. 2005 ,Dec; 289(6): F1170-82.

64. Baum M, Schiavi S, Dwarakanath V, Quigley R: Effect of fibroblast growth factor-23 on phosphate transport in proximal tubules. Kidney Int 2005, Sep; 68(3):1148 - 53. 
65. Yamashita T,Konishi M, Miyake A, Inui K, Itoh N, Fibroblast growth factor (FGF) 23 inhibits renal phosphate reabsorption by activation of the mitogen activated protein kinase pathway. J Biol Chem. 2002 ;Aug 2;277(31):28265-70.

66. Shimada T, Yamazaki Y, Takahashi M, Hasegawa H, Urakawa I, Oshima T, Ono K, Kakitani M, Tomizuka K, Fujita T,Fukumoto S, Yamashita T, Vitamin D receptor - independent FGF23 actions in regulating phosphate and vitamin D metabolism, Am J Physiol Renal Physiol. 2005; Nov;289(5):F1088-95.

67. Sommer S, Berndt T, Craig T, Kumar R: The phosphatonins and the regulation of phosphate transport and vitamin $D$ metabolism. J Steroid Biochem Mol Biol. 2007; Mar;103(3-5):497-503.

68. Imanishi Y, Inaba M, Nakatsuka K, Nagasue K, Okuno S, Yoshihara A, Miura M, Miyauchi A, Kobayashi K, Miki T, Shoji T, Ishimura E, Nishizawa Y: FGF-23 in patients with end-stage renal disease on hemodialysis, Kidney Int. 2004; May;65(5):1943-6.

69. Isakova T: Fibroblast growth factor 23 and adverse clinical outcomes in chronic kidney disease. Curr Opin Nephrol Hypertens. 2012; May;21(3):334-40.

70. Isakova $\mathrm{T}$, Xie $\mathrm{H}$, Yang $\mathrm{W}$, Xie $\mathrm{D}$, Anderson $\mathrm{AH}$, Scialla J, Wahl P, Gutiérrez OM, Steigerwalt S, He J, Schwartz S, Lo J, Ojo A, Sondheimer J, Hsu CY, Lash J,Leonard M, Kusek JW, Feldman HI, Wolf M: Chronic Renal Insufficiency Cohort (CRIC) Study Group, Fibroblast growth factor 23 and risks of mortality and end-stage renal disease in patients with chronic kidney disease. JAMA. 2011 ; Jun 15;305(23):2432-9.

71. Canziani ME, Tomiyama C, Higa A, Draibe SA, Carvalho AB: Fibroblast growth factor 23 in chronic kidney disease: bridging the gap between bone mineral metabolism andleft ventricular hypertrophy. Blood Purif. 2011;31(1$3): 26-32$. 
72. Olauson H, Qureshi AR, Miyamoto T, Barany P, Heimburger O, Lindholm $B$, Stenvinkel P, Larsson TE: Relation between serum fibroblast growth factor23 level and mortality in incident dialysis patients: are genderand cardiovascular disease confounding the relationship?.Nephrol Dial Transplant. 2010 Sep;25(9):3033-8.

73. Go AS, Chertow GM, Fan D, McCulloch CE, Hsu CY: Chronic kidney disease and the risks of death, cardiovascular events, and hospitalization. $N$ Engl J Med. 2004; Sep 23;351(13):1296-305.

74. Bastos M.G.; KIRSZTAJN, G. M: Doença renal crônica: importância do diagnóstico precoce, encaminhamento imediato e abordagem interdisciplinar estruturada para melhora do desfecho em pacientes ainda não submetidos à diálise. J Bras Nefrol 2011;33(1): 93-108.

75. Smart NA, Dieberg G, Ladhani M, Titus T: Early referral to specialist nephrology services for preventing the progression to end-stage kidney disease. Cochrane Database Syst Rev. 2014; Jun 18;6:CD007333.

76. Diegoli H, Silva MC, Machado DS, Cruz CE: Late nephrologist referral and mortality assotiation in dialytic patients. J Bras Nefrol. 2015 ;JanMar;37(1):32-7.

77. Kumar S, Bogle R, Banerjee D: Why do young people with chronic kidney disease die early ?. World J Nephrol. 2014; Nov 6;3(4):143-55.

78. Jimenez ZN, Pereira BJ, Romão JE Jr, Makida SC, Abensur H, Moyses RM, Elias RM: Ankle-brachial index: a simple way to predict mortality among patients on hemodialysis--a prospective study. PLoS One. 2012;7(7):e 42290.

79. The Cochrane Database of Systematic Reviews - Issue 102013 Acesso 23/07/2015. 
80. Drew DA, Lok CE, Cohen JT, Wagner M, Tangri N, Weiner DE: Vascular access choice in incident hemodialysis patients: a decision analysis, $J$ Am Soc Nephrol. 2015 Jan;26(1):183-91.

81. Sachdeva M, Hung A, Kovalchuk O, Bitzer M, Mokrzycki MH, The initial vascular access type contributes to inflammation in incident hemodial ysis patients, Int J Nephrol. 2012;2012:917465.

82. Astor BC, Eustace JA, Powe NR, Klag MJ, Fink NE, Coresh J; CHOICE Study: Type of vascular access and survival among incident hemodialysis patients: the Choices for Healthy Outcomesin Caring for ESRD (CHOICE) Study. J Am Soc Nephrol. 2005 May;16(5):1449-55.

83. Banerjee T, Kim SJ, Astor B, Shafi T, Coresh J, Powe NR: Vascular access type, inflammatory markers, and mortality in incident hemodialysis patients: the Choices forHealthy Outcomes in Caring for End-Stage Renal Disease (CHOICE) Study. Am J Kidney Dis. 2014 ;Dec;64(6):954-61.

84. Casey JR, Hanson CS, Winkelmayer WC, Craig JC, Palmer S, Strippoli GF, Tong A: Patients' perspectives on hemodialysis vascular access: a systematic review of qualitative studies. Am J Kidney Dis. 2014; Dec; 64(6):93753.

85. Perl J, Wald R, McFarlane P, Bargman JM, Vonesh E, Na Y, Jassal SV, Moist: L, Hemodialysis vascular access modifies the association between dialysis modality and survival. J Am Soc Nephrol. 2011; Jun;22 (6):1113-2.

86. Ocak G, Halbesma N, le Cessie S, Hoogeveen EK, van Dijk S, Kooman J, Dekker FW, Krediet RT, Boeschoten EW, Verduijn M: Haemodialysis catheters increase mortality as compared to arteriovenous accesses especially in elderly patients. Nephrol Dial Transplant. 2011;Aug; 26 (8): 2611-7. 
87. Malas MB, Canner JK, Hicks CW, Arhuidese IJ, Zarkowsky DS, Qazi U, Schneider EB, Black JH 3rd, Segev DL, Freischlag JA: Trends in incident hemodialysis access and mortality. JAMA Surg. 2015; May; 150 (5):441-8.

88. Pisoni RL, Arrington CJ, Albert JM, Ethier J, Kimata N, Krishnan M, Rayner HC, Saito A, Sands JJ, Saran R, Gillespie B, Wolfe RA, Port FK: Facility hemodialysis vascular access use and mortality in countries participating in DOPPS: an instrumentalvariable analysis. Am J Kidney Dis 2009; Mar; 53 (3):475-91.

89. Kosa SD, Lok CE: The economics of hemodialysis catheter-related infection prophylaxis. Semin Dial. 2013; Jul-Aug; 26 (4):482-93.

90. Hayashi T, Suzuki A, Shoji T, Togawa M, Okada N, Tsubakihara Y, Imai E, Hori M : Cardiovascular effect of normalizing the hematocrit level during erythropoietin therapy in predialysis patients with chronic renal failure. Am J Kidney Dis. 2000 Feb; 35 (2): 250-6.

91. Fouque D, Pelletier S, Mafra D, Chauveau P: Nutrition and chronic kidney disease. Kidney Int. 2011 Aug; 80(4): 348 - 57.

92. Machowska A, Carrero JJ, Lindholm B, Stenvinkel P: Therapeutics targeting persistent inflammation in chronic kidney disease. Transl Res. 2015 ;Jun 25. pii: S1931-5244(15)00217-0.

93. Unger MD, Cuppari L, Titan SM, Magalhães MC, Sassaki AL, dos Reis LM, Jorgetti V, Moysés RM: Vitamin D status in a sunny country: where has the sun gone?. Clin Nutr. 2010; Dec;29(6):784-8.

94. Obi $\mathrm{Y}$, Hamano $\mathrm{T}$, Isaka $\mathrm{Y}$ : Prevalence and prognostic implications of vitamin $D$ deficiency in chronic kidney disease. Dis Markers. 2015;2015:868961. 
95. Cozzolino M, Messa P, Brancaccio D, Cannella G, Bolasco P, Di Luca M, Costanzo AM, Paparatti Ud, Festa V, Gualberti G, Mazzaferro S; FARO Study Group : Achievement of NKF/K-DOQI recommended target values for bone and mineral metabolism in incident hemodialysis patients: results of the FARO-2 cohort. Blood Purif. 2014;38(1):37-45.

96. Tangri N, Wagner M, Griffith JL, Miskulin DC, Hodsman A, Ansell D, Naimark DM: Effect of bone mineral guideline target achievement on mortality in incident dialysis patients:an analysis of the United Kingdom Renal Registry.Am J Kidney Dis. 2011; Mar;57(3):415-21.

97. Gutiérrez OM, Mannstadt M, Isakova $T$, Rauh-Hain JA, Tamez H, Shah $A$, Smith $K$, Lee $H$, Thadhani $R$, Jüppner $H$, Wolf M: Fibroblast growth factor 23 and mortality among patients undergoing hemodialysis. N Engl J Med. 2008 ;Aug 7;359(6):584-92.

98. Silver J, Naveh-Many T: FGF-23 and secondary hyperparathyroidism in chronic kidney disease. Nat Rev Nephrol. 2013 Nov; 9(11):641-9.

99. Gutiérrez OM, Januzzi JL, Isakova $\mathrm{T}$, Laliberte $\mathrm{K}$, Smith $\mathrm{K}$, Collerone G, Sarwar A, Hoffmann U, Coglianese E, Christenson R, Wang TJ, de Filippi C, Wolf M: Fibroblast growth factor 23 and left ventricular hypertrophy in chronic kidney disease. Circulation. 2009 ;May 19;119(19):2545-52.

100. Wang AY, Wai-Kei Lam C: The diagnostic utility of cardiac biomarkers in dialysis patients. Semin Dial. 2012; Jul;25(4):388-96.

101. Gutiérrez OM, Tamez H, Bhan I, Zazra J, Tonelli M, Wolf $M$, Januzzi JL, Chang Y, Thadhani R: N-terminal pro-B-type natriuretic peptide (NTproBNP) concentrations in hemodialysis patients: prognostic value of baseline and follow-up measurements. Clin Chem. 2008; Aug;54(8):1339-48. 
102. Rastogi A: Sevelamer revisited: pleiotropic effects on endothelial and cardiovascular risk factors in chronic kidney diseaseand end-stage renal disease. Ther Adv Cardiovasc Dis. 2013 ;Dec;7(6):322-42.

103. Cancela AL, Oliveira RB, Graciolli FG, dos Reis LM, Barreto F, Barreto DV, Cuppari L, Jorgetti V, Carvalho AB, Canziani ME, Moysés RM: Fibroblast growth factor 23 in hemodialysis patients: effects of phosphate binder , calcitriol and calcium concentration in the dialysate. Nephron Clin Pract. 2011;117(1):c 74-82.

104. Yilmaz MI, Sonmez A, Saglam M, Yaman H, Kilic S, Eyileten T, Caglar K, Oguz Y, Vural A, Yenicesu M, Mallamaci F, Zoccali C: Comparison of calcium acetate and sevelamer on vascular function and fibroblast growth factor 23 in CKD patients: a randomized clinical trial. Am J Kidney Dis. 2012 ; Feb;59(2):177- 85.

105. Harnett JD, Foley RN, Kent GM, Barre PE, Murray D, Parfrey PS, Congestiveheartfailure in dialysis patients: prevalence, incidence, prognosis and risk factors, Kidney Int. 1995 Mar;47(3):884-90.

106. Scott MC., Winters ME: Congestive Heart Failure. Emerg Med Clin North Am. 2015; Aug;33(3):553-62.

107. Charytan DM, Fishbane S, Malyszko J, McCullough PA, Goldsmith D: Cardiorenal Syndrome and the Role of the Bone-Mineral Axis and Anemia. Am J Kidney Dis. 2015; Aug;66(2):196-205.

108. Mills KT, Xu Y, Zhang W, Bundy JD, Chen CS, Kelly TN, Chen J, He J: A systematic analysis of worldwide population based data onthe global burden of chronic kidney disease in2010. Kidney Int. 2015; Nov; 88 (5): 950-7. 


\section{APÊNDICE}

\section{Protocolo clínico}

Nome:

RG:

Idade:

Data nascimento:

Raça: $\square$ Branco $\square$ Não Branco

Sexo: $\square$ Fem $\square$ Masc

1- Etiologia da DRC ( anotar causa)

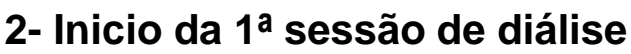

3- Presença de fatores de Risco

A-HAS ( ) Sim （ ) Não

B-Tabagismo ( ) Sim （）Não

C- ICC ( ) Sim ( ) Não

D- Dislipidemia（） Sim （）Não

E- DM ( ) Sim ( ) Não

F-ICo ( ) Sim ( ) Não

G- Insuficiência vascular periférica（）Sim （）Não

4 - Primeiro acesso vascular

( ) Cateter Schilley ( ) Permcath ( ) FAV ( ) Enxerto

5- Acesso Vascular ao final do 1ํㅡㅇ

( ) Cateter Schilley ( ) Permcath ( ) FAV ( ) Enxerto

6-Infecções de acesso vascular ?
( ) Sim
( ) Não

Qual a freqüência no período de 1 ano? (Anotar) 
5- Outros tipos de infecções no período de 1 ano?
( ) $\operatorname{Sim}$
( ) Não

Freqüência -

Tipo -

6- Eventos cardiovasculares em 1 ano?
( ) Sim
( ) Não

Tipo

Freqüência

7- Óbito no período de 1 ano?
( ) $\operatorname{Sim}$
( ) Não

Qual a causa (anotar)

Qual o tempo entre início da Hemodiálise e o óbito (em meses) ?

8- Transplante renal no período de 1 ano?

( ) Sim ( ) Não

Qual o tempo entre o início da terapia dialítica e o Transplante renal (em meses)?

\section{Exames laboratoriais na admissão}

Crea- Uréia - Cai - P- FA - PTH - Hb- Ht -

PCR - Col total- LDL- HDL- Trigl- FGF-23 - 25(OH)D -

1,25(OH)D- Pro BNP - Fe - Ferritina ISAT\% 
Medicações utilizadas no inicio do estudo e ao longo do primeiro ano

Hipotensor ( ) Sim ( ) Não

Quais:

Antiarrítmico: ( ) Sim （）Não Qual:

Antiagregante plaquetário: ( ) Sim ( ) Não Qual:

Hipoglicemiante oral ou parenteral: ( ) Sim （ ) Não

Quais:

Estatinas: ( ) Sim ( ) Não Qual:

Uso de Cálcio: ( ) Sim （）Não

Suplementação ou quelante?

Vitamina D : ( ) Sim （） Não

Calcitriol : ( ) Sim （） Não

Outros quelantes: ( ) Sim （） Não Qual: 